\title{
Article \\ Mathematical Modelling of Glyphosate Molecularly Imprinted Polymer-Based Microsensor with Multiple Phenomena
}

\author{
Fares Zouaoui ${ }^{1}$, Saliha Bourouina-Bacha ${ }^{2} \mathbb{D}$, Mustapha Bourouina ${ }^{2}$, Nadia Zine ${ }^{1}$, Abdelhamid Errachid ${ }^{1}$ and \\ Nicole Jaffrezic-Renault ${ }^{1, *(\mathbb{D})}$
}

1 Institute of Analytical Sciences, University of Lyon, 69100 Villeurbanne, France; fareszou06@gmail.com (F.Z.); nadia.zine@univ-lyon1.fr (N.Z.); abdelhamid.errachid-el-salhi@univ-lyon1.fr (A.E.)

2 Faculty of Technology, University of Bejaia, 06000 Bejaia, Algeria; lgebej@yahoo.fr (S.B.-B.); bouryas@yahoo.fr (M.B.)

* Correspondence: nicole.jaffrezic@univ-lyon1.fr; Tel.: +33-437423516

\section{check for}

updates

Citation: Zouaoui, F.; Bourouina-

Bacha, S.; Bourouina, M.; Zine, N.;

Errachid, A.; Jaffrezic-Renault, N.

Mathematical Modelling of

Glyphosate Molecularly Imprinted

Polymer-Based Microsensor with

Multiple Phenomena. Molecules 2022,

27,493. https://doi.org/10.3390/

molecules27020493

Academic Editors: Naoufel Haddour and Yamina Mounia Azri

Received: 10 December 2021

Accepted: 10 January 2022

Published: 13 January 2022

Publisher's Note: MDPI stays neutral with regard to jurisdictional claims in published maps and institutional affiliations.

Copyright: (c) 2022 by the authors. Licensee MDPI, Basel, Switzerland. This article is an open access article distributed under the terms and conditions of the Creative Commons Attribution (CC BY) license (https:/ / creativecommons.org/licenses/by/ $4.0 /)$.

\begin{abstract}
The massive and careless use of glyphosate (GLY) in agricultural production raises many questions regarding environmental pollution and health risks, it is then important to develop simple methods to detect it. Electrochemical impedance spectroscopy (EIS) is an effective analytical tool for characterizing properties at the electrode/electrolyte interface. It is useful as an analytical procedure, but it can also help in the interpretation of the involved fundamental electrochemical and electronic processes. In this study, the impedance data obtained experimentally for a microsensor based on molecularly imprinted chitosan graft on 4-aminophenylacetic acid for the detection of glyphosate was analyzed using an exact mathematical model based on physical theories. The procedure for modeling experimental responses is well explained. The analysis of the observed impedance response leads to estimations of the microscopic parameters linked to the faradic and capacitive current. The interaction of glyphosate molecules with the imprinted sites of the CS-MIPs film is observed in the high frequency range. The relative variation of the charge transfer resistance is proportional to the $\log$ of the concentration of glyphosate. The capacitance decreases as the concentration of glyphosate increases, which is explained by the discharging of the charged imprinted sites when the glyphosate molecule interacts with the imprinted sites through electrostatic interactions. The phenomenon of adsorption of the ions in the CMA film is observed in the low frequency range, this phenomenon being balanced by the electrostatic interaction of glyphosate with the imprinted sites in the CS-MIPs film.
\end{abstract}

Keywords: mathematical modelling; impedimetric microsensor; molecularly imprinted polymer; glyphosate

\section{Introduction}

Glyphosate (GLY) is a non-selective foliar systemic herbicide [1]. GLY has become the most widely used phytosanitary molecule, especially as a weedkiller in agriculture. It is further used in various non-agricultural contexts such as forestry and household maintenance [2]. Glyphosate can cause harmful effects on animals [3,4], insects and birds [5], variety of animals in the aquatic system [6], microbial, fungal and bacterial biomasses [7]. The relationship between the use of GLY and adverse effects on human health has been the subject of numerous studies. In March 2015, the International Agency for Research on Cancer (IARC, Lyon, France), a department of the World Health Organization (WHO), classified glyphosate as "probably carcinogenic to humans", in 1 'inserting into Category 2A, representing substances with limited evidence of carcinogenicity to humans and sufficient evidence to animals [8]. In May 2016, a joint expert meeting of WHO and the Food and Agriculture Organization of the United Nations (FAO) on pesticide residues in the environment and foods, concluded that "glyphosate is unlikely to present a carcinogenic risk to humans through the diet" [9]. 
Consequently, there is more interest in the development of selective, rapid, simple and inexpensive GLY detection methods. Electrochemical sensors are devices capable of meeting this demand. The main challenge for the electrochemical detection of glyphosate is its low electroactivity below an accessible potential window [10]. Therefore, in order to achieve low concentrations for the detection of GLY, the technique of immobilizing biological elements (antibody, enzyme, microorganism, DNA), on the surface of the working electrode, are generally used for GLY recognition to increase sensitivity and specificity, which are typically lacking in chemical sensors. However, as they are biomolecules, their use is limited to mild conditions of $\mathrm{pH}$, temperature and nature of the medium in order to avoid denaturation of the protein. In addition, the use of these biological elements is not that simple. Their supply and immobilization at the surface of the electrodes are complex $[11,12]$.

Due to the need to overcome these limitations, an alternative has been developed which consists of using molecularly imprinted polymers (MIPs). MIPs were used as a specific recognition material having binding sites of size and shape complementary to target molecules (template). To generate cavity-selective MIPs, a monomer is simply polymerized in the presence of the target molecule and a crosslinking agent resulting in the formation of a highly crosslinked template/monomer complex. MIPs are characterized by very interesting properties such as physical resistance, robustness, resistance to high pressures and temperatures and high inertia towards various chemicals. In addition, MIPs have high affinity and selectivity towards target molecules; they are comparable to natural receptors [13-17].

Sensors based on molecularly imprinted polymers (MIPs) are being developed for the detection of GLY. The functional monomers most often used in synthesis are MCA (N-methacryloyl-L-cysteine) [18] and PPy (Polypyrrole) [19,20].

In these works, the electrochemical detection of glyphosate was obtained by voltammetric methods. A more recent study, using MIP based on polyacrylamide cryogels, glyphosate was detected through capacitive measurements [21].

The choice of the functional monomer in the synthesis of MIPs is an essential step given its capacity to provide complementary interactions with the target molecules [22]. Chitosan (CS) is a natural polysaccharide obtained by deacetylation of chitin which is the most abundant non-toxic, biodegradable and biocompatible natural amino polysaccharide [23]. Chitosan has three types of reactive functional groups, an amine group and two primary and secondary hydroxyl groups. The presence of reactive functional groups on the polysaccharide chain of CS gives it flexibility, excellent film-forming capacity, good adhesion, biocompatibility, high mechanical resistance, possibility of undergoing structural modifications, which makes it suitable for the preparation of MIPs and for the construction of electrochemical sensors [24,25].

CS-MIPs electrochemical sensors have been reported in the state of the art. They are based on the electrodeposition of CS on the surface of the electrodes [26,27]. The electrodeposition of chitosan on a conductive surface by $\mathrm{pH}$ gradient causes release of $\mathrm{H}_{2}$. The blogging of these molecules inside the membrane makes it non-homogeneous [28]. The grafting of chitosan on the diazonium salt by the formation of strong interactions probably leads to more homogeneous membranes and to the resolution of interface problems [29].

Electrochemistry describes the chemical phenomena coupled with reciprocal exchanges of electrical energy when an electrolytic chemical medium interacts with an electrical circuit. It allows atomic scale transformations of matter and generations of different reactive species by transfer of electrons between an electrode and a substrate in an electrolytic solution controlled by an electric current or by a voltage [30]. Consequently, the exchange of electrons at the interface between an electronic conductor and the electrolytic medium containing oxidizer/reducer couples (Ox/Red) corresponds to the field of electrochemical reactions, while the reciprocal electron exchange reaction between different $\mathrm{Ox} /$ Red couples correspond to the field of oxidation-reduction reactions [31].

Electroactive species have several "modes of transport" to reach the site of the electron transfer reaction, namely the electrode / electrolyte interface such as convection, diffusion 
and migration. The phenomena related to the movement of matter can be approached at the microscopic level [30]. The electrochemical process can be affected by the phenomenon of adsorption on the surface of the electrode in contact with the solution. In terms of specific adsorption, electrosorption refers to the formation of a chemical bond between the charged species of the electrolyte and the surface of the electrode [32].

Several electrochemical methods are frequently used for physico-chemical analyzes of the electrode/electrolyte interface, such as conductimetry [33], potentiometry [34], amperometry [35], voltammetry [36], and impedimetric. These electrochemical techniques involve three essential quantities which are the current (I), the potential (E) and the time $(t)$.

Electrochemical impedance spectroscopy (EIS) is one of the non-stationary techniques that allow the analysis of complex electrochemical systems. The EIS has established itself as a very powerful analytical tool given its great ability to study the interfacial properties of electrode/electrolyte [37]. The impedance method consists in imposing a sinusoidal disturbance in low amplitude potential, around a chosen voltage $\mathrm{E}_{0}$, between the working electrode and the reference electrode. The sinusoidal current response is thus measured with a continuous component $\mathrm{I}_{0}$, which corresponds to the potential $\mathrm{E}_{0}\left(\mathrm{I}_{0}\right.$ having a zero value when $E_{0}$ is the dropout potential. This response is accompanied by a phase shift $(\varphi)$ depending on the electrical elements present in the system. This system can be considered as a $\ll$ black box $\gg$, which reacts by emitting a signal I when it is subjected to a disturbance E [38].

This work was focused on the modeling of a glyphosate impedimetric microsensor. It was based on the covalent clawing of molecularly imprinted chitosan on 4-aminophenylacetic acid. Mathematical models based on physical theories are developed to analyze the data obtained experimentally. Analysis of the observed impedimetric response leads to the estimation of the microscopic parameters of the sensors. The validation of the different models is carried out by comparing the experimental and theoretical impedance. The response of 'miniaturized developed' sensors is closely related to the presence of specific molecular sites on the film of the biopolymer at the surface of the working macro-electrode, and also related to factors inherent in the structure of the sensor itself and in its mode of operation. Explaining the operation in the depths of this sensor requires in-depth knowledge of all the parameters involved in such a design.

Modeling is a simplified representation of a real physical system or phenomenon, making it possible to reproduce its functioning, to analyze, to explain and to predict certain aspects. Modeling is a tool which helps to understand the intrinsic mechanisms of these analytical instruments. It makes it possible to find relationships between the variables and the parameters that are supposed to influence the metrological characteristics of these sensors, for example the resistance of the solution, the resistance to charge transfer in the different 'layers' that make up the sensor, or geometry. Modeling is essential for optimization before a device or process goes to market. A "reliable" model is one that will simulate a sensor in real conditions. Therefore, there arises the problem of determining the parameters, which intervene in the equations of the model $[39,40]$.

\section{Materials and Methods}

\subsection{Reagents and Apparatus}

Chitosan (CS, molecular weight $250 \mathrm{kDa}$ with a degree of deacetylation 80-95\%), ethanol (99.8\%), methanol (purity 99.9\%), hydrochloric acid $(37 \%, \mathrm{HCl})$, Sulfuric acid (purity 95\%), 1-Ethyl-3-(3-dimethylaminopropyl)carbodiimide (EDC), 4- aminophenylacetic acid (CMA), sodium nitrite $\left(\mathrm{NaNO}_{2}\right)$, sodium hydroxide $(\mathrm{NaOH})$ and glyphosate $(\mathrm{GLY})$ were obtained from Sigma Aldrich, France. N-Hydroxysuccinimide (NHS) was purchased from Acros Organics, France.

Multichannel potentiostat (Biologic-EC-Lab VMP3) analyser was used for all electrochemical measurements. Transducer with four bare-gold working microelectrodes (WE, $\mathrm{S}=0.64 \mathrm{~mm}^{2} /$ unit), two $\mathrm{Ag} / \mathrm{AgCl}$ reference microelectrodes (RE, $\mathrm{S}=0.13 \mathrm{~mm}^{2} /$ unit) and 
one counter microelectrode $\left(\mathrm{CE}, \mathrm{S}=1.37 \mathrm{~mm}^{2}\right)$. It was fabricated at the National Center for Microelectronics (CNM), CSIC, Barcelona, Spain.

\subsection{Preparation of the Microsensor}

The Au microelectrodes were rinsed with ethanol and deionized water in ultrasound for $10 \mathrm{~min}$ then exposed to UV/ozone for $30 \mathrm{~min}$.

CMA solution ( $3 \mathrm{mM})$ was prepared in an aqueous solution of $\mathrm{NaNO}_{2}(20 \mathrm{mM})$ and $\mathrm{HCl}(20 \mathrm{mM})$. The mixture was stored at $4{ }^{\circ} \mathrm{C}$ for $5 \mathrm{~min}$ to slow down the chemical reaction between the different reagents. CMA was electrodeposited into gold microelectrodes by cyclic voltammetry for 5 cycles from -1.2 to $0.0 \mathrm{~V}$ at scan rate of $50 \mathrm{mV} / \mathrm{s}$. After electrodeposition, the microelectrodes were rinsed with deionized water and dried using nitrogen. Carboxylic functions of CMA were activated by incubating of electrodes for $1 \mathrm{~h}$ in 1-ethyl-3(3 dimethylaminopropyl) carbodiimide (EDC) (0.4 M) and N-Hydroxysuccinimide (NHS) $(0.1 \mathrm{M})$ prepared in absolute ethanol. Then, the devices are rinsed carefully with pure ethanol and dried under light flow.

$0.01 \mathrm{~g} / \mathrm{mL}$ of CS was prepared in $0.1 \mathrm{M}$ acetic acid and ultrasonicated until complete solubilization of CS. Then, $1 \mathrm{mg} / \mathrm{mL}$ of GLY was prepared in CS solution. This mixture was mixed for $2 \mathrm{~h}$ to obtain GLY/CS complex, then the $\mathrm{pH}$ of the solution was adjusted to 5 using $0.1 \mathrm{M} \mathrm{NaOH}$. Drops of GLY/CS were deposited on the microelctrodes modified with CMA for $24 \mathrm{~h}$. Microelectrodes were rinsed with deionized water then they were incubated in $0.5 \mathrm{M} \mathrm{H}_{2} \mathrm{SO}_{4}$ solution for $1 \mathrm{~h}$ to cross-link CS. In the end, GLY has been removed from CS by incubating microelectrodes in acetic acid/methanol solution $(1: 1, v / v)$ for $30 \mathrm{~min}$. Thus, an electrochemical microsensor based on CS molecularly imprinted film modified with CMA was developed for the specific recognition of GLY.

The analytical results and characteristics of the developed microsensor are well presented and detailed in an earlier publication [29].

\subsection{EIS detection Method}

Microsensors was characterized using EIS (Initial potential E $=0.2 \mathrm{~V}$. Highest Freq = $100 \mathrm{khz}$, Lowest Freq $=100 \mathrm{mHz}$ ) in phosphate buffer saline solution (PBS) with $5 \mathrm{mM}$ ferroferricyanide $\left(\left[\mathrm{Fe}(\mathrm{CN})_{6}\right]^{3-/ 4-}\right)$ before and after incubation in deionized water containing different concentration of GLY $(0.31 \mathrm{pg} / \mathrm{mL}$ to $50 \mathrm{ng} / \mathrm{mL})$ for $30 \mathrm{~min}$. EIS was used to investigate changes in charge transfer resistance of the film depending on the GLY concentration.

\section{Modeling of the Microsensor}

\subsection{Mathematical Model}

In the models discussed below, the constituent phases have different conductivity values, but the conductivities are of the same type, they are all either ionic or electronic. The reaction at the electrode may include a charge transfer step with formation of ions adsorbed on the surface of the membranes. This is usually visualized by the presence of a three-phase boundary where the electronic conductor, ionic conductor, and pores meet [41].

The impedance spectrum characterizing the microsensor designed by grafting the molecularly imprinted chitosan onto the diazonium salt (CMA) and its equivalent circuit are shown in Figure 1.

The overall impedance spectrum forms two well separated semicircles: From $100 \mathrm{KHz}$ to $17 \mathrm{~Hz}$ : This first semicircle is associated with a load transfer resistor $\left(\mathrm{R}_{\mathrm{ct} 1}\right)$ in parallel with the constant phase elements (CPE1). At high frequency $(100 \mathrm{KHz})$, the intersection of the impedance curve with the abscissa axis enables the electrolyte resistance $R_{\mathrm{s}}$ to be determined. From $17 \mathrm{~Hz}$ to $100 \mathrm{mHz}$ : this second half-circle is modeled by a load transfer resistor $\left(\mathrm{R}_{\mathrm{ct} 2}\right)$ in parallel with the constant phase elements (CPE2) [42]. 


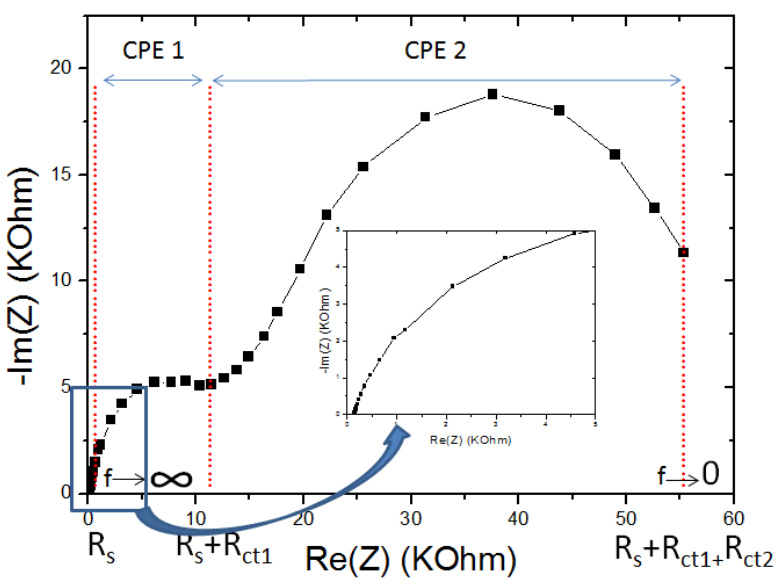

(a)

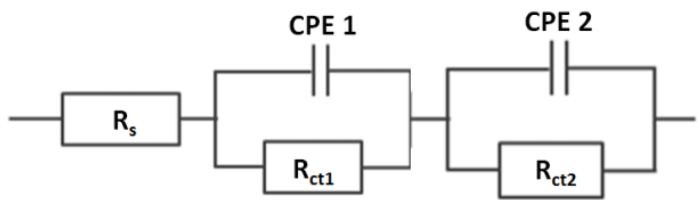

(b)

Figure 1. (a) EIS of the microsensor $(\mathrm{E}=0.2 \mathrm{~V}$. Freq $=100 \mathrm{kHz}-100 \mathrm{mHz}$ ) in PBS with $5 \mathrm{mM}$ $[\mathrm{Fe}(\mathrm{CN}) 6]^{3-/ 4-}$. (b) Equivalent electrical circuit (Rs + CPE1/Rct1+ CPE2/Rct2).

The capacitive current is that associated with the charging or discharging of the electrochemical double layer. The capacitive current does not cause a change in the chemical composition, but only in the distribution of the interfacial electric charges. When a metal is placed in contact with an electrolyte at a given potential, an electrical interface is immediately developed. The area of the metal/solution interface where charged species exist is called the electrical double layer, which then behaves as if an electrical capacitor characterized by a capacitor $C_{\mathrm{dl}}$ [43]. Indeed, it has been established that surface heterogeneities of modified electrodes (roughness, porosity, presence of impurities, absorption on the double layer.) can be the cause of a frequency dispersion of the impedance spectra [44]. In these cases, Constant Phase Element (CPE) are used instead of capacitors to take into account the non-ideality of the system. In the literature, different definitions have been proposed. The CPE formula often used for adjustment is defined by the equation [45]:

$$
\begin{gathered}
Z_{C P E}=\frac{1}{Q(j \omega)^{n}} \\
j=\sqrt{-1}=\cos \left(\frac{\pi}{2}\right)+j \sin \left(\frac{\pi}{2}\right)
\end{gathered}
$$

$\mathrm{Q}$ en $\left(\mathrm{s}^{\mathrm{n}} \Omega^{-1}\right)$ ou $\left(\mathrm{F} \mathrm{s}^{(n-1)}\right)$ represents the CPE coefficient, $-1 \leq n \leq 1$ is the correction factor. $\omega=2 \pi f$, where $\mathrm{f}$ represents the frequency measured in $\mathrm{Hz}$.

In particular, $Z_{C P E}$ represents an inductance if $n=-1$, a resistance if $n=0$, a Warburg impedance if $\mathrm{n}=0.5$ and a capacitance if $\mathrm{n}=1[46,47]$. Equation (1) can also be written:

$$
\mathrm{Z}_{\mathrm{CPE}}=\frac{1}{\mathrm{Q} \omega^{\mathrm{n}}}\left[\cos \left(\mathrm{n} \frac{\pi}{2}\right)-\mathrm{j} \sin \left(\mathrm{n} \frac{\pi}{2}\right)\right]
$$

The global real and imaginary impedances equivalent to the circuit of Figure 1 are given by the following equations:

$$
\begin{gathered}
\operatorname{Re}(Z)=R_{\mathrm{s}}+\frac{\mathrm{R}_{\mathrm{ct} 1}\left(1+\mathrm{R}_{\mathrm{ct} 1} \mathrm{Q}_{1} \omega^{\mathrm{n}_{1}} \cos \frac{\mathrm{n}_{1} \pi}{2}\right)}{1+\left(\mathrm{R}_{\mathrm{ct} 1} \mathrm{Q}_{1} \omega^{\mathrm{n}_{1}}\right)^{2}+2 \mathrm{R}_{\mathrm{ct} 1} \mathrm{Q}_{1} \omega^{\mathrm{n}_{1}} \cos \frac{\mathrm{n}_{1} \pi}{2}}+\frac{\mathrm{R}_{\mathrm{ct} 2}\left(1+\mathrm{R}_{\mathrm{ct} 2} \mathrm{Q}_{2} \omega^{\mathrm{n}_{2}} \cos \frac{\mathrm{n}_{2} \pi}{2}\right)}{1+\left(\mathrm{R}_{\mathrm{ct} 2} \mathrm{Q}_{2} \omega^{\mathrm{n}_{2}}\right)^{2}+2 \mathrm{R}_{\mathrm{ct} 2} \mathrm{Q}_{2} \omega^{\mathrm{n}_{2}} \cos \frac{\mathrm{n}_{2} \pi}{2}} \\
-\operatorname{Im}(\mathrm{Z})=\frac{\mathrm{R}_{\mathrm{ct1}}{ }^{2} \mathrm{Q}_{1} \omega^{\mathrm{n}_{1}} \sin \frac{\mathrm{n}_{1} \pi}{2}}{1+\left(\mathrm{R}_{\mathrm{ct} 1} \mathrm{Q}_{1} \omega^{\mathrm{n}_{1}}\right)^{2}+2 \mathrm{R}_{\mathrm{ct} 1} \mathrm{Q}_{1} \omega^{\mathrm{n}_{1}} \cos \frac{\mathrm{n}_{1} \pi}{2}}+\frac{\mathrm{R}_{\mathrm{ct} 2}{ }^{2} \mathrm{Q}_{2} \omega^{\mathrm{n}_{2}} \sin \frac{\mathrm{n}_{2} \pi}{2}}{1+\left(\mathrm{R}_{\mathrm{ct} 2} \mathrm{Q}_{2} \omega^{\mathrm{n}_{2}}\right)^{2}+2 \mathrm{R}_{\mathrm{ct} 2} \mathrm{Q}_{2} \omega^{\mathrm{n}_{2}} \cos \frac{\mathrm{n}_{2} \pi}{2}}
\end{gathered}
$$


where $\operatorname{Re}(Z)$ is the real part of the impedance, $-\operatorname{Im}(Z)$ is the imaginary part of the impedance. $\mathrm{Q}_{1}$ represents the coefficient of $C P E 1, \mathrm{n}_{1}$ the correction factor of $C P E 1, \mathrm{Q}_{2}$ is the coefficient of CPE2, $\mathrm{n}_{2}$ the correction factor of CPE2.

Changes in potential and current in the electrolyte lead to the concept of ohmic drop described as the electrolyte resistance $R_{s}$. This resistance is an important factor contributing to the global impedance of the cell [48]. The impedance of the resistance of the solution is:

$$
\begin{aligned}
\mathrm{Z}_{\mathrm{R}_{\mathrm{S}}} & =\mathrm{R}_{\mathrm{s}} \\
\mathrm{R}_{\mathrm{s}}(\Omega) & =\rho \frac{l}{\mathrm{~A}}
\end{aligned}
$$

where $\rho$ resistivity of the solution $(\Omega \mathrm{cm}), l$ the coating thickness and $\mathrm{A}$ is the area of the coating [49].

The resistivity of the ferri/ferrocyanide solution is calculated by the following relationships:

$$
\begin{gathered}
\rho=\frac{1}{\sigma} \\
\sigma=\sum_{\mathrm{i}} \mathrm{q}_{\mathrm{i}} \lambda_{\mathrm{i}} \mathrm{C}_{\mathrm{i}}
\end{gathered}
$$

With, $\sigma$ : conductivity of the solution $(\mathrm{s} / \mathrm{m})$ who can be calculate from redox ion couple, $C_{i}$ the concentration of the ion $\left(\mathrm{mol} / \mathrm{m}^{3}\right), \mathrm{q}_{i}$ the number of charges of the ion, $\lambda_{i}$ the equivalent molar ionic conductivity.

The reactions at the electrodes involve the redox couple ferri/ferrocyanide, in which ferricyanide is the oxidant and the ferrocyanide is the reducing agent. For $C_{O x}=C_{R e d}=C$, and for a simple one-electron process $(n=1), R_{c t}$ is given by Equation (10):

$$
\mathrm{R}_{\mathrm{tc}}=\frac{\mathrm{RT}}{\mathrm{F}^{2} \mathrm{Ak}^{0} \mathrm{C}}
$$

With; R: Ideal gas constant $\left(\mathrm{J} \cdot \mathrm{mol}^{-1} \cdot \mathrm{K}^{-1}\right)$, T: Temperature (K), F: Faraday constant $\left(C \cdot \mathrm{mo}^{-1}\right)$, A: surface of the working electrode $\left(\mathrm{cm}^{2}\right), \mathrm{k}^{0}$ standard electron transfer rate constant $(\mathrm{cm} / \mathrm{s})$.

\subsection{Numerical Simulation}

To determine the various parameters and validate the proposed model, the response of the sensor was simulated by using Equations (1) and (2) using Matlab software. The parameters were varied with a very small step (Table 1 ), then the optimal values were determined by minimizing the error between the experimental values and the predicted values. The simulations should make it possible to find the link between the impedance measurement and the various parameters exposed. The developed program consists of two distinct parts. The first part consists in determining the parameters of the circuit $R_{S}+$ $\mathrm{CPE} 1 / \mathrm{R}_{\mathrm{ct} 1}$, after validation of this step the program proceeds to determine the parameters of the circuit CPE2/R $\mathrm{R}_{\mathrm{ct} 2}$.

The error between the experimental and theoretical values is calculated according to the relations (11) and (12). The iterations are stopped when $\mathrm{e}_{1}, \mathrm{e}_{2} \leq \mathrm{e}_{0}\left(10^{-3}\right)$.

$$
\begin{gathered}
\text { Error }\left(\mathrm{e}_{1}\right)=\sum\left|\frac{\operatorname{Re}(\mathrm{Z})_{\text {theoretical }}-\operatorname{Re}(\mathrm{Z})_{\text {experimental }}}{\operatorname{Re}(\mathrm{Z})_{\text {theoretical }}}\right| \\
\text { Error }\left(\mathrm{e}_{2}\right)=\sum\left|\frac{(-\operatorname{Im}(\mathrm{Z}))_{\text {theoritical }}-(-\operatorname{Im}(\mathrm{Z}))_{\text {experimental }}}{(-\operatorname{Im}(\mathrm{Z}))_{\text {theoretical }}}\right|
\end{gathered}
$$


Table 1. Variation interval of different parameters.

\begin{tabular}{ccc}
\hline Parameters & Variation Range & Unit \\
\hline$l$ & {$\left[10^{-3}, 10^{-5}\right]$} & $\mathrm{cm}$ \\
\hline $\mathrm{k}_{1}{ }^{\circ}$ & {$\left[10^{-3}, 10^{-5}\right]$} & $\mathrm{cm} \cdot \mathrm{s}^{-1}$ \\
\hline $\mathrm{Q}_{1}$ & {$\left[10^{-5}, 10^{-8}\right]$} & $\mathrm{s}^{\mathrm{n}} \cdot \Omega^{-1}$ \\
\hline $\mathrm{n}_{1}$ & {$[-1,1]$} & $/$ \\
\hline $\mathrm{k}_{2}{ }^{\circ}$ & {$\left[10^{-3}, 10^{-5}\right]$} & $\mathrm{cm} \cdot \mathrm{s}^{-1}$ \\
\hline $\mathrm{Q}_{2}$ & {$\left[10^{-5}, 10^{-8}\right]$} & $\mathrm{s}^{\mathrm{n}} \cdot \Omega^{-1}$ \\
\hline $\mathrm{n}_{2}$ & {$[-1,1]$} & $/$ \\
\hline
\end{tabular}

\section{Results and Discussions}

\subsection{Model Validation}

In order to validate the physical model, the simulation results are compared with the experimental data. We have obtained the results presented in Figure 2. We can first see that the results obtained theoretically are consistent with the experimental values obtained in ref [28]. Thus, the proposed physical model is in agreement with our simulations and it showed good agreement with the results obtained in the laboratory. Overall, the errors are less than $10^{-3}$.

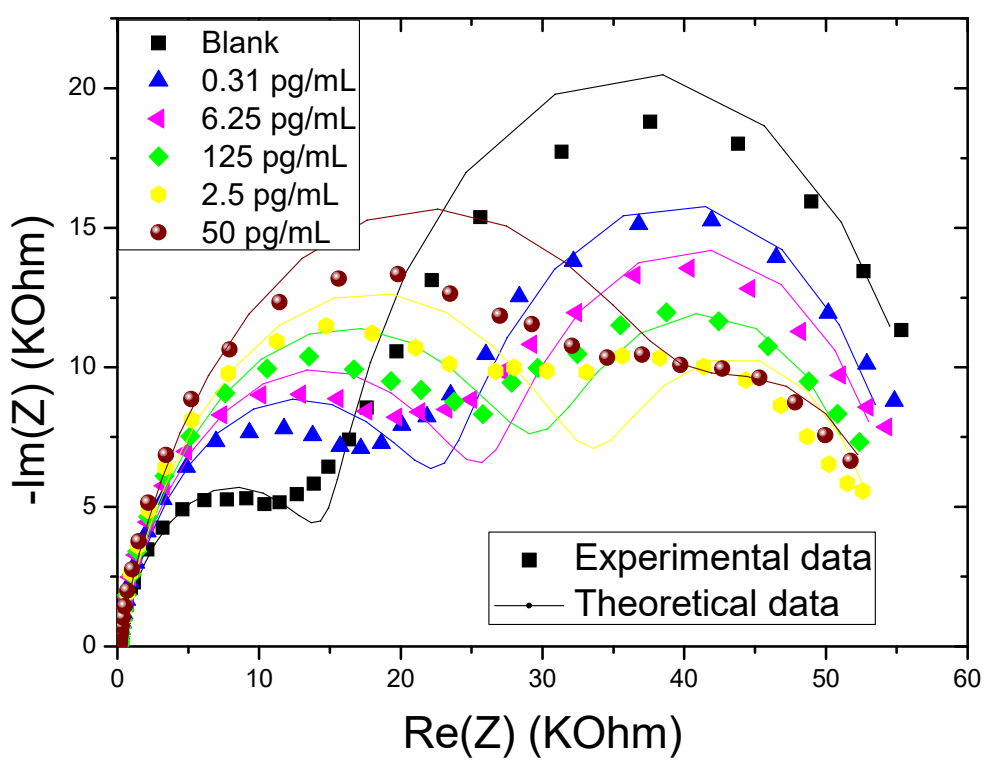

Figure 2. Experimental and theoretical EIS of CS-MIPs/CMA/ $\mathrm{Au}$ in $5 \mathrm{mM}[\mathrm{Fe}(\mathrm{CN}) 6]^{3-/ 4-}$ initial potential $\mathrm{E}=0.2 \mathrm{~V} ; \mathrm{f}=100 \mathrm{kHz}-100 \mathrm{mHz}$, for different concentrations of GLY $(0.31 \mathrm{pg} / \mathrm{mL}-$ $6.25 \mathrm{pg} / \mathrm{mL}-125 \mathrm{pg} / \mathrm{mL}-2.5 \mathrm{ng} / \mathrm{mL}$ and $50 \mathrm{ng} / \mathrm{mL}$ ).

\subsection{Analysis of Theoretical Results}

The values of each parameter of the model are presented in Table 2. The thickness of the membranes (CS + CMA) deposited on the electrode determined by the model is $36 \mu \mathrm{m}$. This value was found to vary of less than $1 \mu \mathrm{m}$ from one sensor to another. This thickness is constant throughout the experiment indicating the stability of the sensor in the analysis medium. Thus, the resistance of the solution $R_{S}$ is $151,14 \mathrm{Ohm}$, this resistance is also constant during the experiment. 
Table 2. Different parameters of CS-MIPs/CMA/Au estimated by the model for different concentrations of GLY.

\begin{tabular}{|c|c|c|c|c|c|c|c|c|c|c|c|c|}
\hline [GLY] & $\begin{array}{c}l \\
(\mu \mathrm{m})\end{array}$ & $\begin{array}{l}R_{s} \\
(\Omega)\end{array}$ & $\begin{array}{c}\mathbf{k}_{1}^{\circ} \\
(\mu \mathrm{m} / \mathrm{s})\end{array}$ & $\begin{array}{l}R_{\text {ct1 }} \\
(\Omega)\end{array}$ & $\begin{array}{c}Q_{1} \cdot 10^{7} \\
\left(S^{n} \Omega^{-1}\right)\end{array}$ & $\mathbf{n}_{1}$ & $\begin{array}{c}\mathrm{k}_{2}^{\circ} \\
(\mu \mathrm{m} / \mathrm{s})\end{array}$ & $\begin{array}{l}R_{\mathrm{ct} 2} \\
(\Omega)\end{array}$ & $\begin{array}{c}Q_{2} \cdot 10^{5} \\
\left(S^{n} \Omega^{-1}\right)\end{array}$ & $\mathbf{n}_{2}$ & $\mathrm{e}_{1} \times 10^{4}$ & $e_{2} \times 10^{4}$ \\
\hline Blank & 36 & 151.14 & 5.5 & 15,132 & 5.60 & 0.79 & 1.92 & 43,348 & 1.07 & 0.96 & 4.20 & 3.59 \\
\hline $0.31 \mathrm{pg} / \mathrm{mL}$ & 36 & 151.14 & 3.5 & 23,779 & 5.45 & 0.79 & 2.25 & 32,638 & 1.40 & 0.96 & 7.04 & 3.88 \\
\hline $6.25 \mathrm{pg} / \mathrm{mL}$ & 36 & 151.14 & 3.1 & 26,848 & 5.17 & 0.79 & 2.87 & 28,999 & 1.65 & 0.96 & 6.52 & 6.84 \\
\hline $125 \mathrm{pg} / \mathrm{mL}$ & 36 & 151.14 & 2.7 & 30,825 & 5.02 & 0.79 & 3.58 & 23,248 & 1.77 & 0.96 & 7.50 & 9.94 \\
\hline $2.5 \mathrm{ng} / \mathrm{mL}$ & 36 & 151.14 & 2.4 & 34,678 & 4.86 & 0.79 & 4.17 & 19,959 & 2.08 & 0.96 & 0.98 & 0.38 \\
\hline $50 \mathrm{ng} / \mathrm{mL}$ & 36 & 151.14 & 2.0 & 41,614 & 4.56 & 0.79 & 5.21 & 14,083 & 2.30 & 0.96 & 2.88 & 9.57 \\
\hline
\end{tabular}

For the parameters of the first semi-circle, the value of the standard rate constant $\mathrm{k}_{1}{ }^{\circ}$ decreases with the increase in the concentration of the incubated GLY, going from $5,5 \mu \mathrm{m} / \mathrm{s}$ to $2 \mu \mathrm{m} / \mathrm{s}$ according to a linear law whose equation is $\left(\mathrm{k}_{1}^{\circ}=-0.284 \log [\mathrm{GLY}]+4.19\right)$ with a correlation coefficient $R^{2}=0.997$ (Figure 3a). The decrease in the electron transfer rate caused an increase in the charge transfer resistance $R_{\mathrm{ct} 1}$, this linear variation is given by the following regression equation $\left(\mathrm{k}_{1}{ }^{\circ}=-8.285 \mathrm{R}_{\mathrm{ct} 1}+5.35 ; \mathrm{R}^{2}=0.961\right)$ (Figure $3 \mathrm{~b}$ ). The increase in $R_{\mathrm{ct} 1}$ is proportional to the increase in GLY concentration. It went from $15132 \mathrm{Ohm}$ for a zero GLY concentration to $41614 \mathrm{Ohm}$ for a concentration of $50 \mathrm{ng} / \mathrm{mL}$ of incubated GLY $\left(\mathrm{R}_{\mathrm{ct} 1}=3343.5 \log [\mathrm{GLY}]+14507.2 ; \mathrm{R}^{2}=0.966\right)$ (Figure 3c). Moreover, the value of $\mathrm{Q}_{1}$, associated with the behavior of CPE1, is inversely proportional to the concentration of GLY going from $5.6 \times 10^{-7} \mathrm{~S}^{\mathrm{n}} \cdot \Omega^{-1}([\mathrm{GLY}]=0)$ to $4.56 \times 10^{-7} \mathrm{~S}^{\mathrm{n}} \cdot \Omega^{-1}$ $([\mathrm{GLY}]=50 \mathrm{ng} / \mathrm{mL})\left(\mathrm{Q}_{1}=-0.16 \times 10^{-7} \log [\mathrm{GLY}]+5.83 \times 10^{-7} ; \mathrm{R}^{2}=0.977\right)$ (Figure 3d). The value of $n_{1}$ which is 0.79 indicates that the surface is inhomogeneous. $n_{1}$ being close to 1 , it means that CPE1, included in the model, is nearly a pure capacitance.

The value of $Q_{1}$ decreases with increasing GLY concentration. This decrease makes it possible to conclude that the capacitance of the CS-MIPs film and the concentration of GLY are inversely proportional. The same behavior has been observed in the state of the art where the capacitance of a MIPs sensor based on N, N-methylenebisacrylamide cryogel varies inversely proportional with the concentration of glyphosate [21]. The phenomenon was explained by the discharging of the charged imprinted sites when the glyphosate molecule interacts with the imprinted sites through electrostatic interactions.

Regarding the parameters of the second semi-circle, the rate constant $\mathrm{k}_{2}{ }^{\circ}$ and the coefficient $\mathrm{Q}_{2}$ increase proportionally with the increase in the concentration of the incubated GLY. $\mathrm{k}_{2}{ }^{\circ}$ went from $1.92 \mu \mathrm{m} / \mathrm{s}$ to $5.21 \mu \mathrm{m} / \mathrm{s}\left(\mathrm{k}_{2}{ }^{\circ}=0.55 \log [\mathrm{GLY}]+0.78 ; \mathrm{R}^{2}=0.986\right)$ (Figure $4 \mathrm{a})$, while $\mathrm{Q}$ went from $1.07 \times 10^{-5} \mathrm{~S}^{\mathrm{n}} \cdot \Omega^{-1}$ to $2.3 \times 10^{-5} \mathrm{~S}^{\mathrm{n}} \cdot \Omega^{-1}\left(\mathrm{Q}_{2}=0.1714 \times\right.$ $10^{-5} \log [\mathrm{GLY}]+0.966 \times 10^{-5} ; \mathrm{R}^{2}=0.983$ ) (Figure $4 \mathrm{~d}$ ). While the resistance to load transfer decreases and it varies linearly as a function of the speed constant $\mathrm{k}_{2}{ }^{\circ}\left(\mathrm{k}_{2}{ }^{\circ}=-1.563 \mathrm{R}_{\mathrm{ct} 2}+\right.$ 7.334; $R^{2}=0.993$ ) (Figure $4 \mathrm{~b}$ ) and as a function of the logarithm of the GLY concentration $\left(R_{\mathrm{ct} 2}=-3547.1 \log [\mathrm{GLY}]+41865.1 ; \mathrm{R}^{2}=0.989\right)($ Figure $4 \mathrm{c})$. These variations are recorded with the change from a zero incubated concentration to a concentration of $50 \mathrm{ng} / \mathrm{mL}$ of glyphosate. As for the factor $n_{2}$, its value is estimated at 0.96 indicating that the surface is more relatively homogeneous.

Note that the constituent phases have different values of conductivity. $\mathrm{R}_{\mathrm{ct} 1}, \mathrm{k}_{1}{ }^{\circ}, \mathrm{n}_{1}$ and $\mathrm{Q}_{1}$ describe the processes that occur in the membrane of chitosan. Consequently, all the variations recorded on these parameters are due to the variation in the concentration of glyphosate in the membrane of MIPs, the greater this concentration; the more the film is resistive, thus causing a decrease in the faradic and capacitive current. 


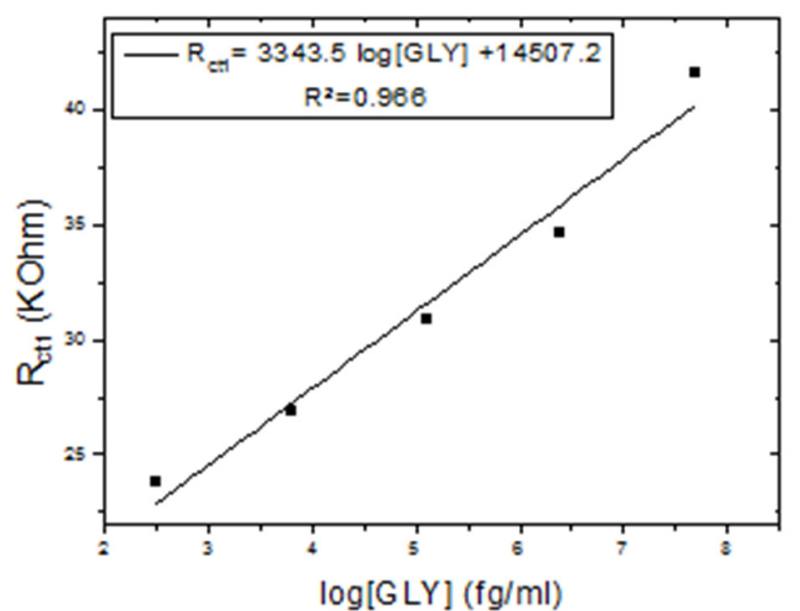

(a)

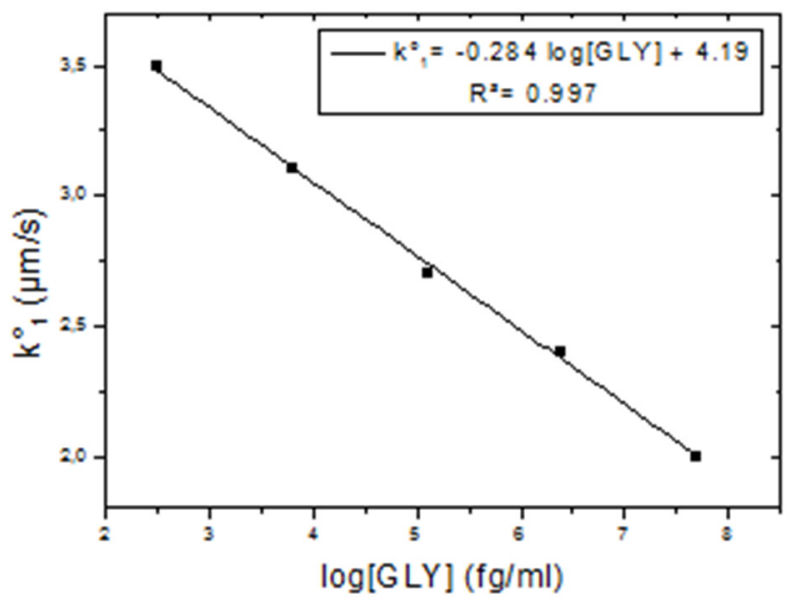

(c)

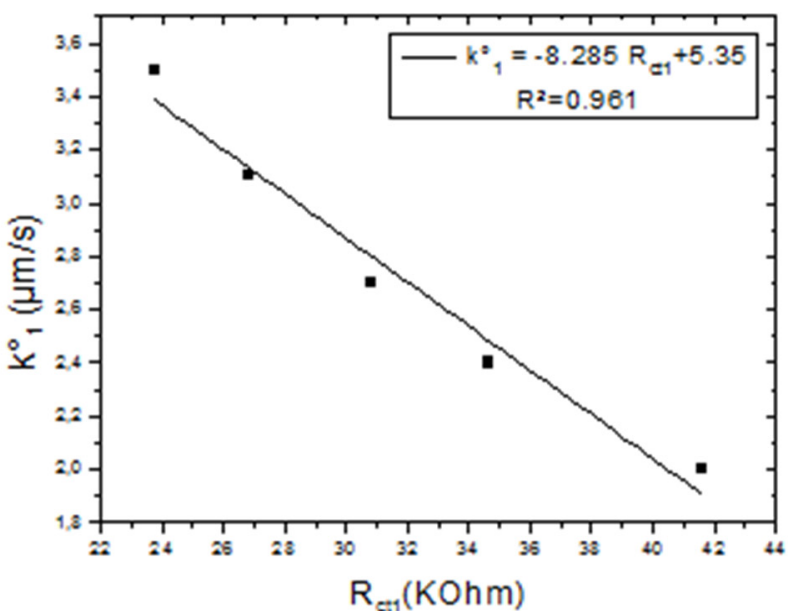

(b)

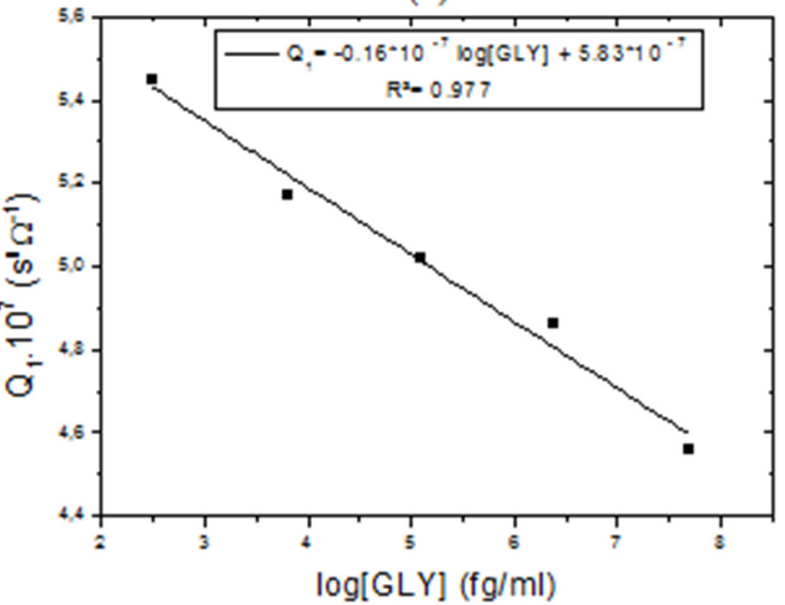

(d)

Figure 3. Calibration curves of CS-MIPs/CMA/Au. (a) $k_{1}{ }^{\circ}=f(\log [G L Y]),(b) k_{1}{ }^{\circ}=f(R c t 1)$ for different [GLY], (c) $\mathrm{R}_{\mathrm{ct} 1}=\mathrm{f}(\log [\mathrm{GLY}]),(\mathrm{d}) \mathrm{Q}_{1}=\mathrm{f}(\log [\mathrm{GLY}])$. ([GLY] $=0.31 \mathrm{pg} / \mathrm{mL}-6.25 \mathrm{pg} / \mathrm{mL}-$ $125 \mathrm{pg} / \mathrm{mL}-2.5 \mathrm{ng} / \mathrm{mL}-50 \mathrm{ng} / \mathrm{mL})$.

While $\mathrm{R}_{\mathrm{ct} 2}, \mathrm{k}_{2}{ }^{\circ}, \mathrm{n}_{2}$ and $\mathrm{Q}_{2}$ correspond to the film of CMA which separates the membrane MIPs from the surface of the sensor, as it can also represent the polarization of the electrode. The impedance of the polarizable electrode can be represented as a parallel connection of the charge transfer resistor and the double layer capacitor. It was assumed in the literature that such a distribution could result from a microscopic roughness always present on the solid surfaces, as it can be caused by a dispersion of the capacitance of interfacial origin, linked to the adsorption of ions and to in homogeneities surface chemicals. The concentration of the redox couple changes in the pores with an exponential gradient. This problem has been addressed in the literature [50,51]. The accumulation of ions on the electrode surface causes an increase in faradic and capacitive current.

The relative variation of the resistance to charge transfer of the electrode is presented using the following equation $\left|R_{c t 1}-R_{c t 1 b l a n k}\right| / R_{c t 1 b l a n k}(\Delta R / R)$. The calculations of $\Delta R / R$ were carried out with Rct1, which is related to the variation in the concentration of GLY. This parameter is found to be linearly proportional to the logarithmic value of GLY concentrations in the range of $0.31 \mathrm{pg} / \mathrm{mL}$ to $50 \mathrm{ng} / \mathrm{mL}$, as shown in Figure 5, with a correlation coefficient of 0.999 . The linear regression equation is: $\Delta R / R=0.221 \log [G L Y]-0.02$. 


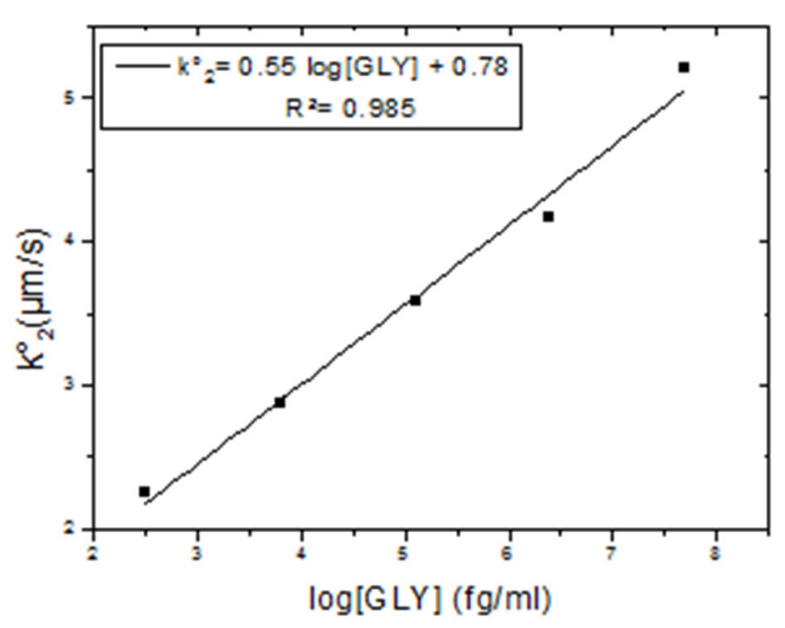

(a)

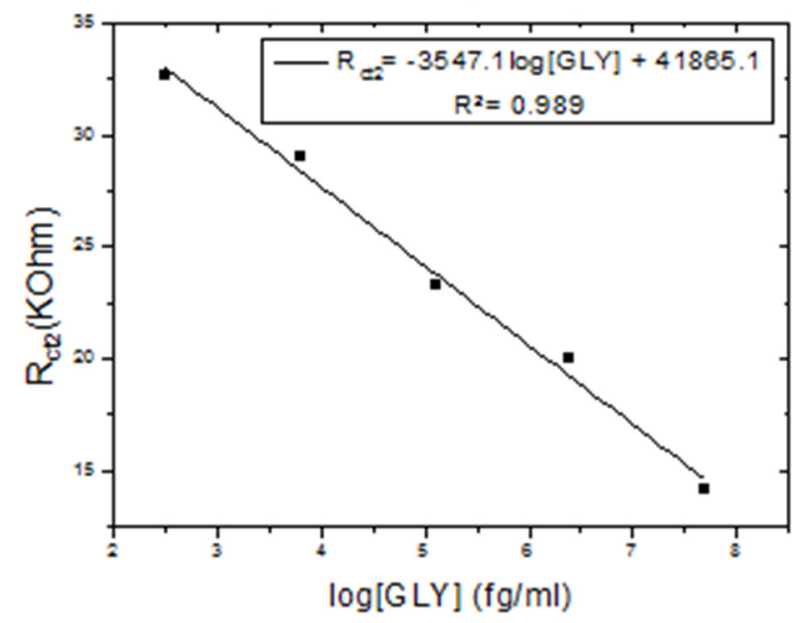

(c)

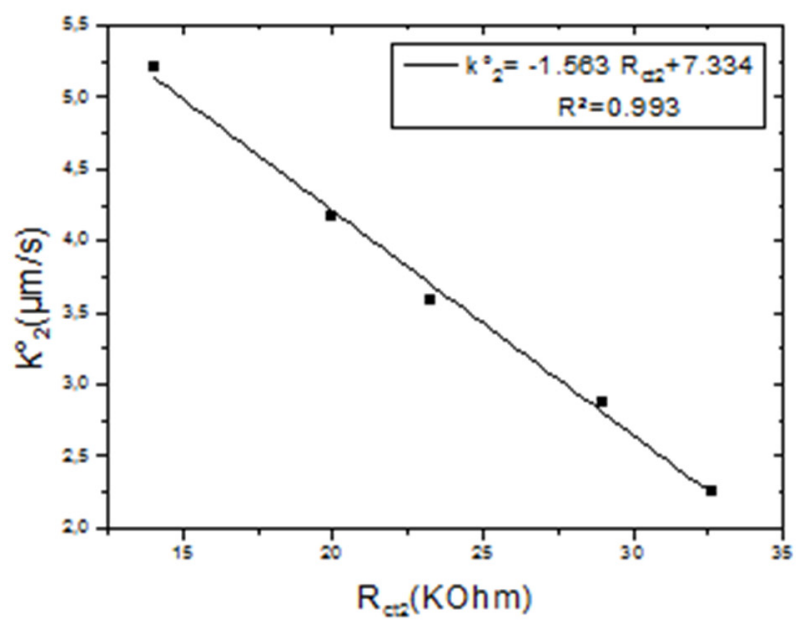

(b)

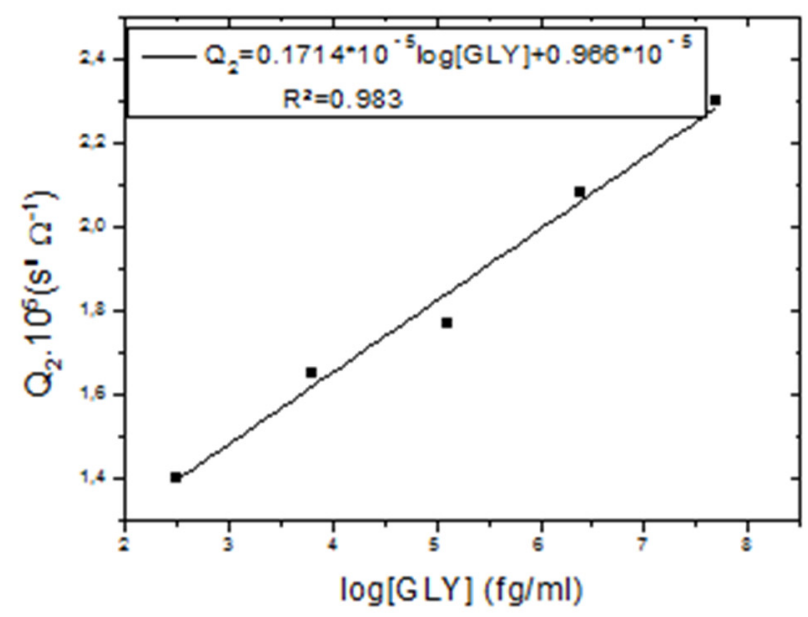

(d)

Figure 4. Calibration curves of CS-MIPs/CMA/Au. (a) $k_{2}{ }^{\circ}=f(\log [G L Y]),(b) k_{2}{ }^{\circ}=f(R c t 2)$ for different [GLY], (c) $R_{\mathrm{ct} 2}=\mathrm{f}(\log [\mathrm{GLY}]),(\mathrm{d}) \mathrm{Q}_{2}=\mathrm{f}(\log [\mathrm{GLY}])$. ([GLY] $=0.31 \mathrm{pg} / \mathrm{mL}-6.25 \mathrm{pg} / \mathrm{mL}-$ $125 \mathrm{pg} / \mathrm{mL}-2.5 \mathrm{ng} / \mathrm{mL}-50 \mathrm{ng} / \mathrm{mL})$.

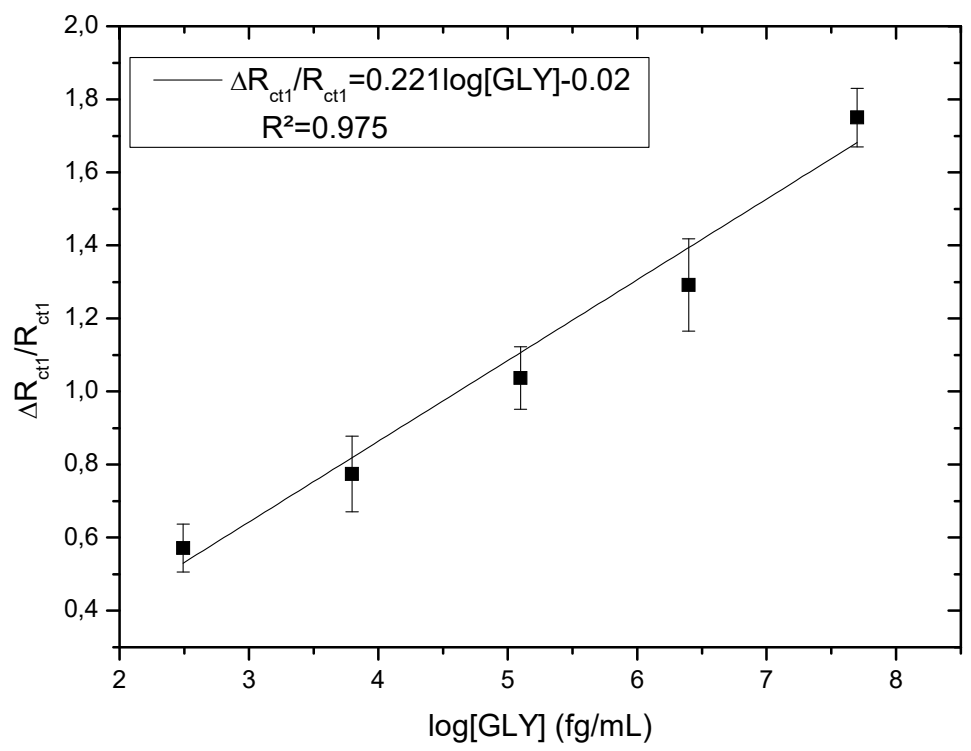

Figure 5. Calibration curves of CS-MIPs /CMA/ $\mathrm{Au}\left(\Delta \mathrm{R} / \mathrm{R}=0.221 \log [\mathrm{GLY}]-0.02 ; \mathrm{R}^{2}=0.975\right)$. 
The detection limit (LOD) of the considered sensor is estimated at $1 \mathrm{fg} / \mathrm{mL}$. LOD was obtained from the equation $3 \mathrm{~S} / \mathrm{m}$ [52], where $S$ is the residual standard deviation of the linear regression and $\mathrm{m}$ is the slope of the regression line. The results showed a low detection limit and high sensitivity.

The parameters of the CS-MIPs/CMA/Au sensor are compared to another impedancemeter sensor for the detection of GLY which is based on electropolymerized polypyrrole films, as a conductive layer layer between the gold microelectrode surface and the molecularly imprinted chitosan film (CS-MIPs/PPy/Au) [27]. The impedance spectrum of the PPy-based sensor is formed by a single semicircle. This result allows concluding that in the present work, the formation of two half-circles in the impedance spectrum is due to the presence of the CMA. The electron transfer rate in the MIPs films of the CS-MIPs/PPy/Au sensor is much higher $(55 \mu \mathrm{m} / \mathrm{s})$ than that of the CS-MIPs/CMA/Au $(5.5 \mu \mathrm{m} / \mathrm{s})$ sensor due to the presence of the PPy conductive layer which facilitates the electron transfer. The interest of the covalent attachment of the CS-MIPs film on an underlayer is to eliminate the inhomogeneity of the CS-MIPs film caused by the trapping of the $\mathrm{H}_{2}$ molecules released during the electrodeposition of the CS film. Due to the insulating property of the CMA film, accumulation of charged species occurred (second semi-circle in the low frequency range), which is not the case using polypyrrole film [27].

Despite this enormous difference, the sensitivities of both sensors (with PPy and with CMA), calculated with the relative resistance variation $(R / R)$, are close $(0.30$ for CS-MIPs/PPy/Au and 0.221 for CS-MIPs/CMA/Au), the detection limits are the same: $1 \mathrm{fg} / \mathrm{mL}$ and their possible recyclability is the same.

\subsection{Comparison between MIPs and NIP}

The response of the NIP sensor was modeled with the model developed. Figure 6 shows the theoretical and experimental evolution of $\operatorname{Re}(Z)$ as a function of $-\operatorname{Im}(Z)$. A good fit is achieved between the experimental data and the theoretical data with a fairly low error $\left(<10^{-3}\right)$. The parameters of the NIP sensor are listed in Table 3. These parameters vary insignificantly depending on the concentration of GLY, in particular $R_{\mathrm{ct} 1}$. From this point, it comes that the non-specific adsorption of glyphosate is very low.

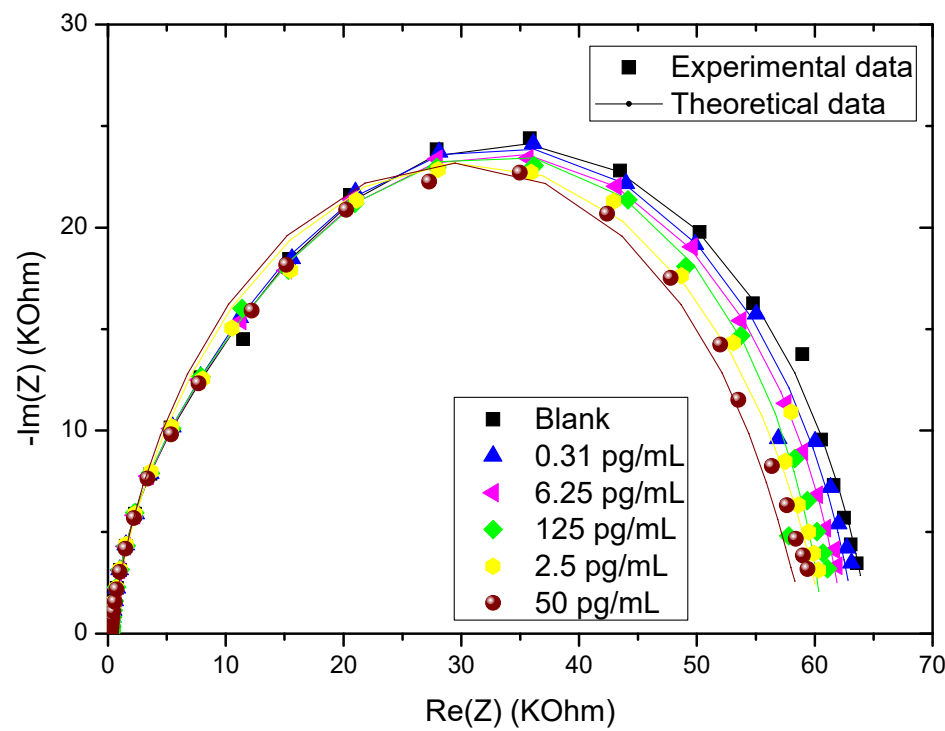

Figure 6. Experimental and theoretical EIS of CS-MIPs/CMA/ $\mathrm{Au}$ in $5 \mathrm{mM}[\mathrm{Fe}(\mathrm{CN}) 6]^{3-/ 4-}$ initial potential $\mathrm{E}=0.2 \mathrm{~V} ; \mathrm{f}=100 \mathrm{kHz}-100 \mathrm{mHz}$, for different concentrations of GLY $(0.31 \mathrm{pg} / \mathrm{mL}-$ $6.25 \mathrm{pg} / \mathrm{mL}-125 \mathrm{pg} / \mathrm{mL}-2.5 \mathrm{ng} / \mathrm{mL}$ and $50 \mathrm{ng} / \mathrm{mL}$ ). 
Table 3. Different parameters of CS-NIP/CMA/Au estimated by the model for different concentrations of GLY.

\begin{tabular}{|c|c|c|c|c|c|c|c|c|c|c|c|c|}
\hline [GLY] & $\begin{array}{c}l \\
(\mu \mathrm{m})\end{array}$ & $\begin{array}{c}R_{s} \\
(\Omega)\end{array}$ & $\begin{array}{c}k_{1}^{\circ} \\
(\mu \mathrm{m} / \mathrm{s})\end{array}$ & $\begin{array}{l}R_{\mathrm{ct1}} \\
(\Omega)\end{array}$ & $\begin{array}{c}\mathrm{Q}_{1} \cdot 10^{7} \\
\left(\mathrm{~S}^{\mathrm{n}} \Omega^{-1}\right)\end{array}$ & $\mathbf{n}_{1}$ & $\begin{array}{c}k_{2}^{\circ} \\
(\mu \mathrm{m} / \mathrm{s})\end{array}$ & $\begin{array}{l}R_{\mathrm{ct2}} \\
(\Omega)\end{array}$ & $\begin{array}{c}\mathrm{Q}_{2} \cdot 10^{7} \\
\left(\mathrm{~S}^{\mathrm{n}} \Omega^{-1}\right)\end{array}$ & $\mathbf{n}_{2}$ & $e_{1} \times 10^{4}$ & $e_{2} \times 10^{4}$ \\
\hline Blank & 56.8 & 238.5 & 1.39 & 59,563 & 4.92 & 0.85 & 17.02 & 4885 & 3.56 & 0.98 & 2.22 & 4.96 \\
\hline $0.31 \mathrm{pg} / \mathrm{mL}$ & 56.8 & 238.5 & 1.41 & 58,850 & 4.65 & 0.85 & 18.60 & 4469 & 3.81 & 0.98 & 4.15 & 3.58 \\
\hline $6.25 \mathrm{pg} / \mathrm{mL}$ & 56.8 & 238.5 & 1.36 & 61,271 & 4.71 & 0.85 & 13.09 & 6349 & 4.02 & 0.98 & 3.54 & 5.51 \\
\hline $125 \mathrm{pg} / \mathrm{mL}$ & 56.8 & 238.5 & 1.45 & 57,234 & 4.44 & 0.85 & 8.98 & 9257 & 4.21 & 0.98 & 5.63 & 8.36 \\
\hline $2.5 \mathrm{ng} / \mathrm{mL}$ & 56.8 & 238.5 & 1.39 & 59,571 & 4.86 & 0.85 & 9.28 & 8953 & 3.85 & 0.98 & 5.45 & 4.48 \\
\hline $50 \mathrm{ng} / \mathrm{mL}$ & 56.8 & 238.5 & 1.43 & 58,223 & 4.64 & 0.85 & 9.50 & 8742 & 3.66 & 0.98 & 4.48 & 4.22 \\
\hline
\end{tabular}

The coating thickness of the NIP sensor $(56.8 \mu \mathrm{m})$ is greater than that of the MIPs $(36 \mu \mathrm{m})$. Therefore, the resistance of the resulting solution is greater on the NIP sensor (238.5 Ohm) compared to MIP (151.14 Ohm).

The value $\mathrm{n} 1$ of the MIPs film $\left(\mathrm{n}_{1}=0.79\right)$ is lower than that of the NIP $\left(\mathrm{n}_{1}=0.85\right)$ which makes it possible to say that the MIPs films are more porous due to the presence of free sites, specific to GLY. This point can also explain the compared values of the electron transfer rate constants: the electron transfer rate constant in the MIPs film is greater $\left(\mathrm{k}_{1}{ }^{\circ}=5.5 \mu \mathrm{m} / \mathrm{s}\right)$ compared to the NIP film $\left(\mathrm{k}_{1}{ }^{\circ}=1.4 \mu \mathrm{m} / \mathrm{s}\right)$. The values of $\mathrm{n} 2$ characterizing the CMA films are close indicating that there is not a big difference in the morphology of the two films $\left(\mathrm{n}_{2}(\mathrm{MIPs})=0.96-\mathrm{n}_{2}(\mathrm{NIP})=0.98\right)$.

\subsection{Effects of Differents Parameters on the Impedance Response of CS-MIPs/CMA/Au}

\subsubsection{Effect of Coefficient $n$}

The coefficient $\mathrm{n}_{1}$ has an effect on the impedance of the first semicircle which is found at high frequencies. The more $n_{1}$ decreases the more the maximum of $-\operatorname{Im}(Z)$ of the first semicircle and its value at the end towards the middle frequencies decreases, in contrast with the minimum value of $\operatorname{Re}(Z)$ which increases and its maximum remains constant. The coefficient $\mathrm{n}_{1}$ has no effect on the second semi-circle, except for the initial value of the imaginary impedance $-\operatorname{Im}(Z)$ (Figure 7a).

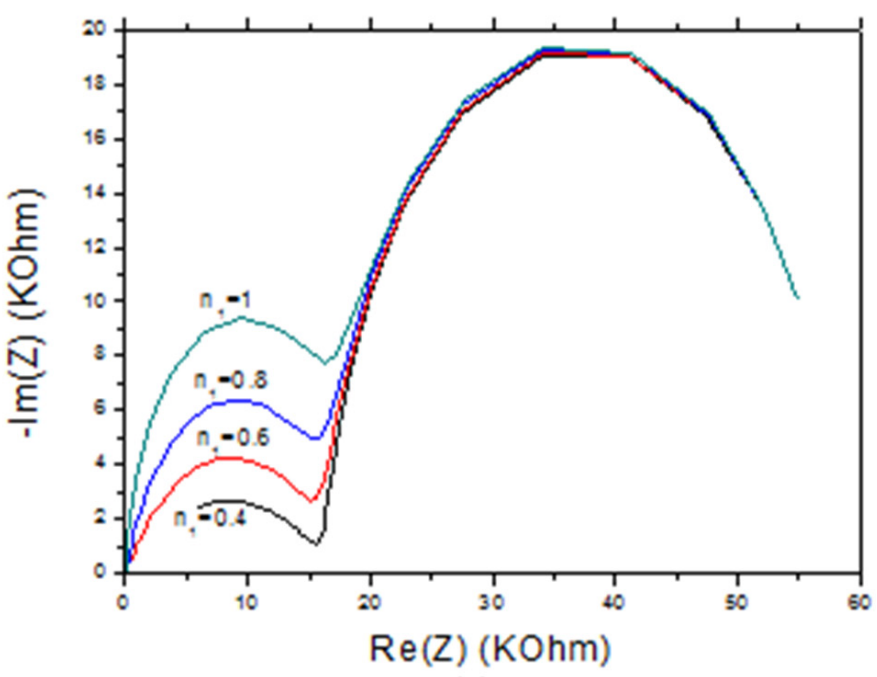

(a)

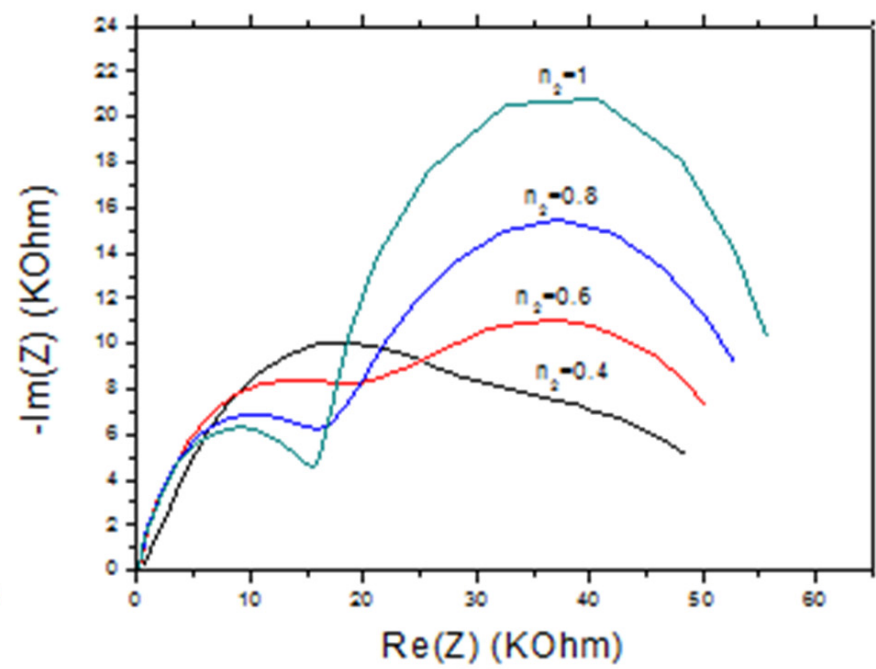

(b)

Figure 7. (a) Effect of coefficient $\mathrm{n} 1$ on the variation of the impedance response of CS-MIPs/CMA/Au for $n_{2}=0.95$. (b) Effect of coefficient $\mathrm{n}_{2}$ on the variation of the impedance response of CSMIPs/CMA/ $\mathrm{Au}$ for $\mathrm{n}_{1}=0.8$. In $5 \mathrm{mM}\left[\mathrm{Fe}(\mathrm{CN})_{6}\right]^{3-/ 4-} . \mathrm{f}=100 \mathrm{kHz}-100 \mathrm{mHz} . \mathrm{A}=0.0064 \mathrm{~cm}^{2}$, $\mathrm{T}=298 \mathrm{~K}, l=36 \mu \mathrm{m}, \mathrm{k}_{1}{ }^{\circ}=5 \mu \mathrm{m} / \mathrm{s}, \mathrm{Q}_{1}=5 \times 10^{-7} \mathrm{~s}^{\mathrm{n}} \Omega^{-1}, \mathrm{k}_{2}{ }^{\circ}=2 \mu \mathrm{m} / \mathrm{s}, \mathrm{Q}_{2}=10^{-5} \mathrm{~s}^{\mathrm{n}} \Omega^{-1}$. 
With the reduction of the coefficient $\mathrm{n}_{2}$ we notice that the maximum of Re.

Experimentally, $n_{1}$ and $n_{2}$ can be modified by varying the thickness of the CMA and MIP films, respectively. These parameters can be controlled by varying the number of cycles during the electrodeposition. In addition, $\mathrm{n}_{2}$ can be decreased by the use of a porogene solvent in the synthesis of the CS-MIPs [53], which can cause increase the porosity and tortuosity on the CS film.

(Z) and of $-\operatorname{Im}(Z)$ of the first semicircle increases, and that a better definition of the semicircle is obtained for a maximum value $n 2$. For the second semicircle, the maxima of $\operatorname{Re}(Z)$ and $-\operatorname{Im}(Z)$ in the low frequency domain decrease with the decrease in $n_{2}$. The larger $\mathrm{n}_{2}$, the more well defined this semicircle (Figure $7 \mathrm{~b}$ ).

\subsubsection{Effect of the Standard Rate Constant $\mathrm{k}^{\circ}$}

With the decrease in the value of $\mathrm{k}_{1}{ }^{\circ}$ from $10^{-2}$ to $10^{-3} \mathrm{~cm} / \mathrm{s}$ we notice that the real and imaginary impedance of the first semi-circle has increased, for the second semi-circle the maximum of $-\operatorname{Im}(\mathrm{Z})$ remained constant and the real impedance increased. The passage at a speed $\mathrm{k}_{1}{ }^{\circ}$ of $10^{-4} \mathrm{~cm} / \mathrm{s}$ recorded a significant increase in the imaginary impedance of the first semicircle, while the maximum of the real impedance remained the same as for $\mathrm{k}_{1}{ }^{\circ}$ equal to $10^{-3} \mathrm{~cm} / \mathrm{s}$. For the second semicircle, while it is less defined, the maximum value of $-\operatorname{Im}(Z)$ is larger and that of $\operatorname{Re}(Z)$ is smaller than the values recorded for $k_{1}{ }^{\circ}$ equal to $10^{-3} \mathrm{~cm} / \mathrm{s}$. With the decrease in $\mathrm{k}_{1}{ }^{\circ}$, we notice the appearance of a single semicircle with greater resistance (Figure 8), which is observed for the NIP film.

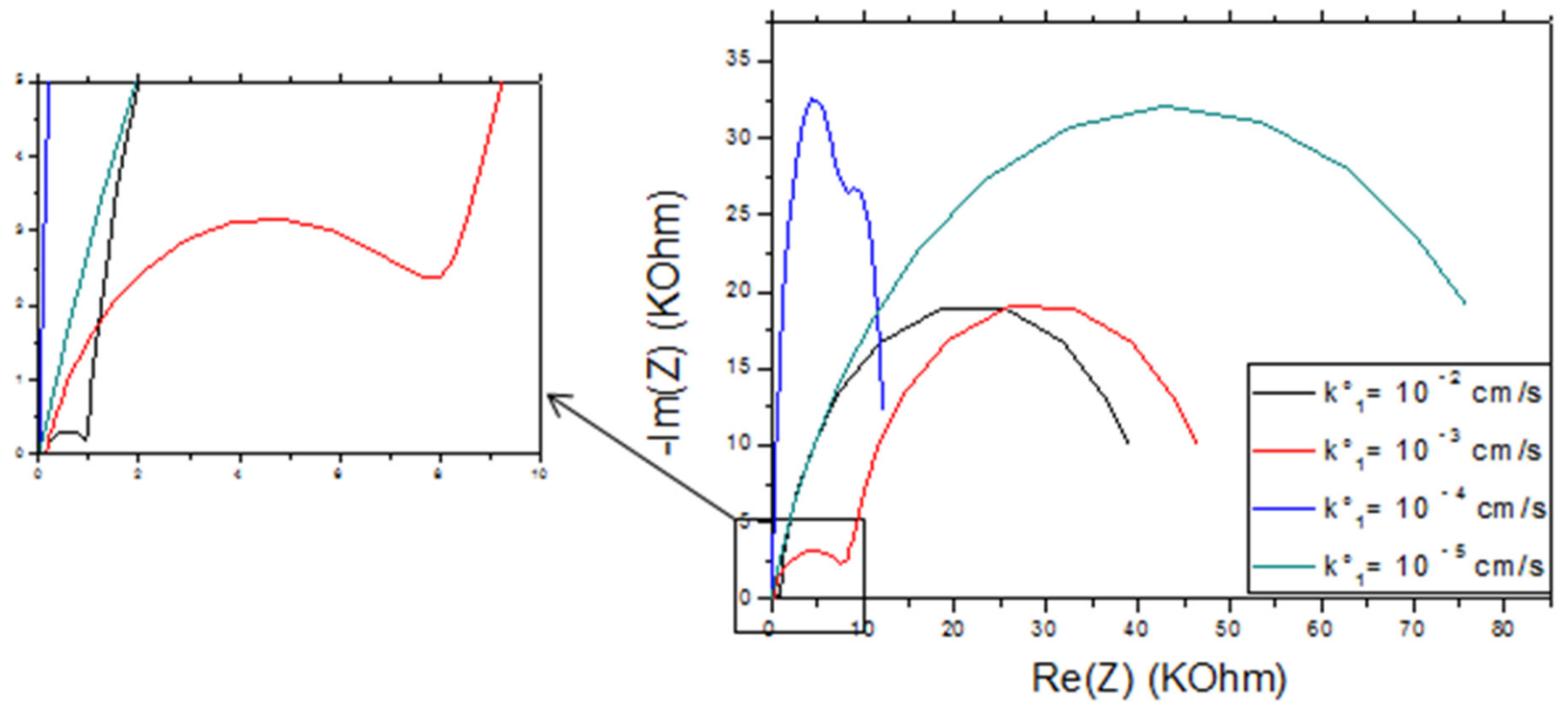

Figure 8. Effect of the rate constant $\mathrm{k}_{1}{ }^{\circ}$ on the impedance response of CS-MIPs/CMA/Au. For $\mathrm{T}=298 \mathrm{~K}, \mathrm{~A}=0.0064 \mathrm{~cm}^{2}, l=60 \mu \mathrm{m}, \mathrm{Q}_{1}=5 \times 10^{-7} \mathrm{~s}^{\mathrm{n}} \Omega^{-1}, \mathrm{n}_{1}=0.8, \mathrm{k}_{2}{ }^{\circ}=2 \mu \mathrm{m} / \mathrm{s}, \mathrm{Q}_{2}=10^{-5} \mathrm{~s}^{\mathrm{n}} \Omega^{-1}$, $\mathrm{n}_{2}=0.95 .\left[\mathrm{Fe}(\mathrm{CN})_{6}\right]^{3-/ 4-}=5 \mathrm{mM} . \mathrm{f}=100 \mathrm{KHz}-100 \mathrm{mHz}$.

In Figure 9, we have shown the effect of varying the rate constant $\mathrm{k}_{2}{ }^{\circ}$ on the impedance spectrum. For large values of $\mathrm{k}_{2}{ }^{\circ}$ we notice the appearance of a spectrum with a single semicircle. With the decrease in $\mathrm{k}_{2}{ }^{\circ}$, two semicircles appear on the spectrum. The maximum of $\operatorname{Re}(Z)$ of the first semicircle remains constant, and the maximum of - Im (Z) decreases with the decrease of $k_{2}{ }^{\circ}$. Whereas, for the second semicircle, the maximum of $-\operatorname{Im}(Z)$ decreases and that of $\operatorname{Re}(Z)$ increases with the decrease $k_{2}{ }^{\circ}$. For sufficiently low values of $k_{2}{ }^{\circ}$, we notice that the semi-circle at low frequencies approaches the shape of a semi-infinite line. 


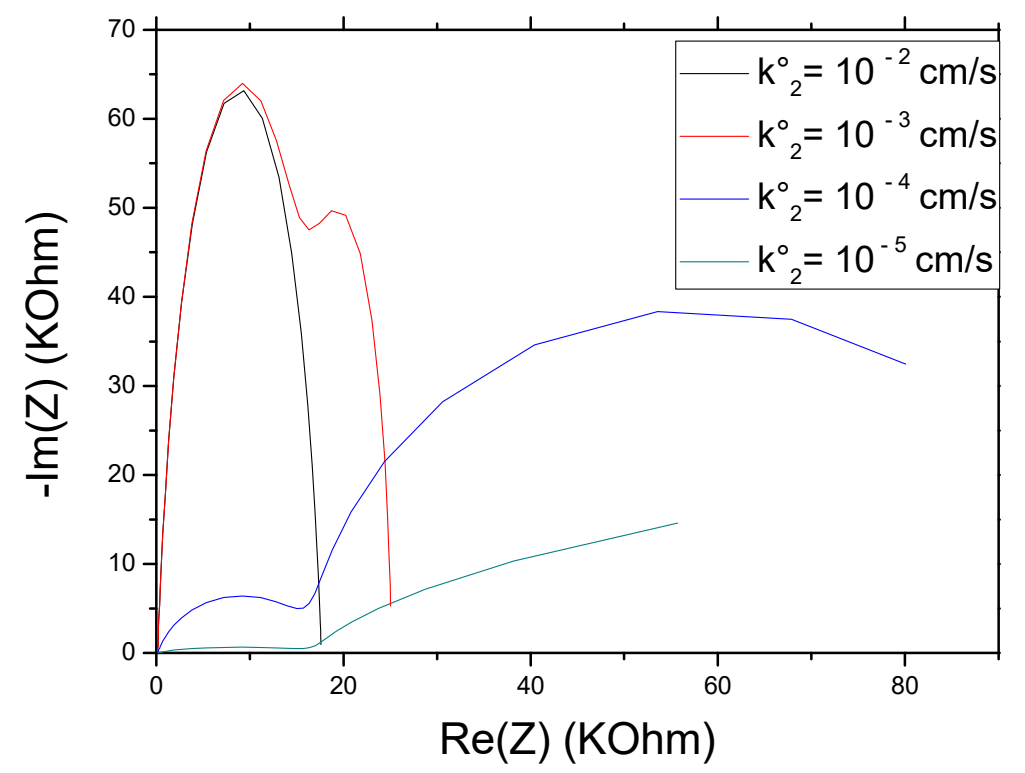

Figure 9. Effect of the rate constant $\mathrm{k}_{2}{ }^{\circ}$ on the impedance response of CS-MIPs/CMA/Au. For $\mathrm{T}=298 \mathrm{~K}, \mathrm{~A}=0.0064 \mathrm{~cm}^{2}, l=60 \mu \mathrm{m}, \mathrm{k}_{1}^{\circ}=5 \mu \mathrm{m} / \mathrm{s}, \mathrm{Q}_{1}=5 \times 10^{-7}, \mathrm{n}_{1}=0.8 \mathrm{~s}^{\mathrm{n}} \Omega^{-1}, \mathrm{Q}_{2}=10^{-5} \mathrm{~s}^{\mathrm{n}} \Omega^{-1}$, $\mathrm{n}_{2}=0.95 .\left[\mathrm{Fe}(\mathrm{CN})_{6}\right]^{3-/ 4-}=5 \mathrm{mM} . \mathrm{f}=100 \mathrm{KHz}-100 \mathrm{mHz}$.

For obtaining a higher value of $\mathrm{k}_{1}{ }^{\circ}$ and $\mathrm{k}_{2}{ }^{\circ}$, the thickness of the two films should be decreased allowing to reduce the charge transfer resistance. On another side, increasing of the concentration of the redox couple should be increased the values of $k_{1}{ }^{\circ}$ and $k_{2}{ }^{\circ}$. Or, for example, the integration of conductive nanomaterials in the CS and CMA films could also increase the value of $\mathrm{k}^{\circ}$.

\subsubsection{Effect of Coefficient Q}

For larger values of $Q_{1}$, the model gives a spectrum with a single semicircle (Figure 10a). With the decrease in the value of $Q_{1}$, we obtain spectra with two semi-circles. The latter is more defined for a minimum $Q_{1}$ value. On the two semicircles, the maximum of $-\operatorname{Im}(Z)$ varies little, and the maximum of $\operatorname{Re}(Z)$ remains constant.

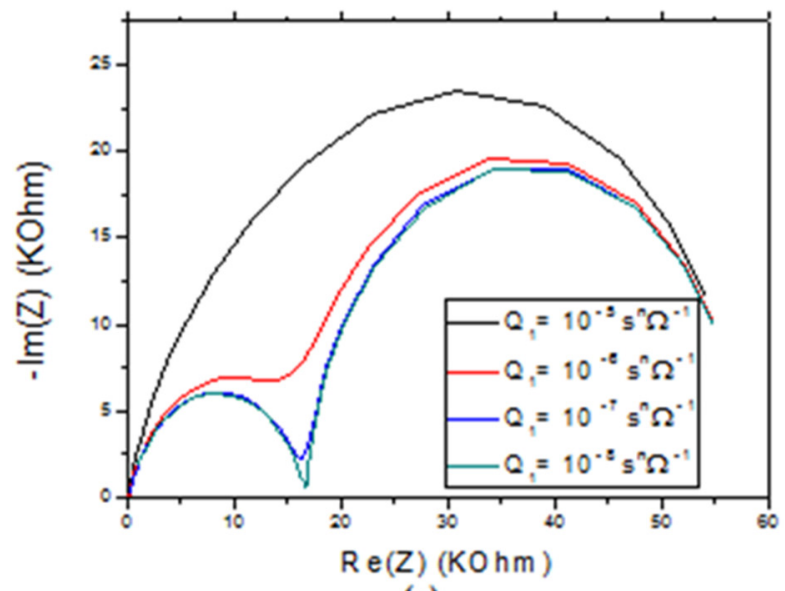

(a)

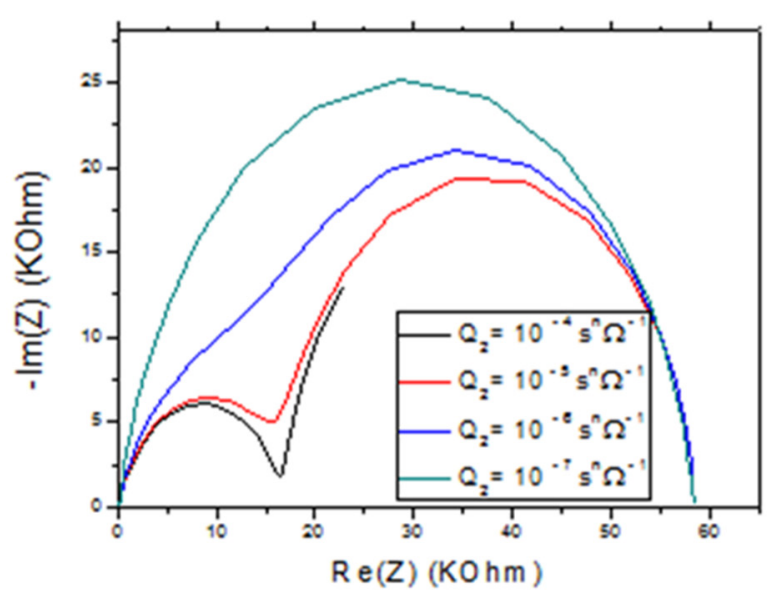

(b)

Figure 10. (a) Effect of the rate constant $Q_{1}$ on the impedance response of CS-MIPs/CMA/Au for $\mathrm{Q}_{2}=10^{-5} \mathrm{~s}^{\mathrm{n}} \Omega^{-1}$. (b) Effect of the rate constant $\mathrm{Q}_{2}$ on the impedance response of CS-MIPs/CMA/Au for $\mathrm{Q}_{1}=5 \times 10^{-7} . \mathrm{T}=298 \mathrm{~K}, \mathrm{~A}=0.0064 \mathrm{~cm}^{2}, l=60 \mu \mathrm{m}, \mathrm{k}_{1}{ }^{\circ}=5 \mu \mathrm{m} / \mathrm{s}, \mathrm{Q}_{1}=5 \times 10^{-7} \mathrm{~s}^{\mathrm{n}} \Omega^{-1}$, $\mathrm{Q}_{2}=10^{-5} \mathrm{~s}^{\mathrm{n}} \Omega^{-1}, \mathrm{n}_{1}=0.8, \mathrm{n}_{2}=0.95 .\left[\mathrm{Fe}(\mathrm{CN})_{6}\right]^{3-/ 4-}=5 \mathrm{mM} . \mathrm{f}=100 \mathrm{KHz}-100 \mathrm{mHz}$. 
With the variation of the coefficient of CPE $\left(Q_{2}\right)$, we obtain a single semicircle for low values of $\mathrm{Q}_{2}$. With the increase of $\mathrm{Q}_{2}$ the model gives two increasingly better-defined semicircles. The maximum of $-\operatorname{Im}(Z)$ varies little, and the maximum of $\operatorname{Re}(Z)$ remains constant. For sufficiently large values in $\mathrm{Q}_{2}$ we notice the disappearance of part of the second semi-circle which is located towards the low frequency areas (Figure 10b).

So, the sensor is better if the thickness of the electronic double layer is low. $Q_{1}$ and $Q_{2}$ can be decreased by the variation of the movement of the ions by agitation of the electrolyte, by increasing of the temperature, by the variation of the applied potential, or also the changes in the morphology of the CS and CMA films [54-56].

\section{Conclusions}

The desire to understand the intrinsic operating mechanisms of the developed microsensor, or to open up new avenues in the implementation of new design processes, requires in-depth knowledge of all the parameters of influence. In this study, the impedimetric response of the CS-MIPs/CMA/Au microsensors has been modeled using mathematical model based on physical laws. The phenomena at the electrode/electrolyte interface were described. The various parameters were determined by minimizing the error between the experimental and theoretical values. Then, the effect of each parameter and GLY concentration on the response signal was shown. The first half-circle in the high frequency range is due to the interaction of glyphosate molecules with the imprinted sites of the CS-MIPs film. The relative variation of the charge transfer resistance is proportional to the log of the concentration of glyphosate. The capacitance decreases as the concentration of glyphosate increases, which is explained by the discharging of the charged imprinted sites when the glyphosate molecule interacts with the imprinted sites through electrostatic interactions. The second half-circle of impedance in the low frequency range is due to the phenomenon of adsorption of the ions in the CMA film, this phenomenon being balanced by the electrostatic interaction of glyphosate with the imprinted sites in the CS-MIPs film. This phenomenon is due to the insulating properties of the CMA film but is not observed when CS-MIPs film is attached to a conductive film such as polypyrrole. Despite these differences of electrochemical behavior, CS-MIPs/CMA/Au and CS-MIPs/PPy/Au microsensors present the same detection limit: $1 \mathrm{fg} / \mathrm{mL}$.

The developed model here for a MIP-chitosan based sensor is applicable to other MIP based sensors. It appears here that electrostatic interactions between template and imprinted sites induce changes in capacitance. The effect of the electrical properties of an underlayer can change the morphology the Nyquist plot. The morphology of the Nyquist plot of the NIP based sensor is totally different from that of the corresponding MIP based sensor.

In order to increase the sensitivity of detection, some improvements could be brought in the preparation of the MIP-based sensor: the thickness of MIP film and of its underlayer should be obtained thinner, the conductivity of the underlayer should be improved by the addition of conductive nanomaterials, the porosity of the MIP film should be improved by using a porogene, the concentration of the redox probe could be increased.

Author Contributions: Investigation, F.Z.; resources, A.E.; writing—original draft preparation, N.Z.; writing-review and editing, N.J.-R.; supervision, S.B.-B. and M.B. All authors have read and agreed to the published version of the manuscript.

Funding: The authors acknowledge the financial support of the EU H2020 WIDESPREAD Program entitled Bionanosens grant agreement \# 951887.

Informed Consent Statement: Not applicable.

Data Availability Statement: The data that support the findings of this study are available from the corresponding author upon reasonable request.

Conflicts of Interest: The authors declare no conflict of interest. 


\section{References}

1. Valavanidis, A. Glyphosate, the most widely used herbicide. In Health and Safety Issues. Why Scientists Differ in Their Evaluation of Its Adverse Health Effects; University Campus Zografou: Athens, Greece, 2018.

2. Torretta, V.; Katsoyiannis, I.; Viotti, P.; Rada, E. Critical Review of the Effects of Glyphosate Exposure to the Environment and Humans through the Food Supply Chain. Sustainability 2018, 10, 950. [CrossRef]

3. Krüger, M.; Schledorn, P.; Schrödl, W.; Hoppe, H.-W.; Lutz, W.; Shehata, A.A. Detection of Glyphosate Residues in Animals and Humans. J. Environ. Anal. Toxicol. 2014, 4, 1-5.

4. Séralini, G.-E.; Clair, E.; Mesnage, R.; Gress, S.; Defarge, N.; Malatesta, M.; Hennequin, D.; de Vendômois, J.S. Republished Study: Long-Term Toxicity of a Roundup Herbicide and a Roundup-Tolerantgenetically Modified Maize. Environ. Sci. Eur. 2014, 26, 1-17. [CrossRef]

5. Herbert, L.T.; Vázquez, D.E.; Arenas, A.; Farina, W.M. Effects of Field-Realistic Doses of Glyphosate on Honeybee Appetitive Behaviour. J. Exp. Biol. 2014, 217, 3457-3464. [CrossRef] [PubMed]

6. Van Bruggen, A.H.C.; He, M.M.; Shin, K.; Mai, V.; Jeong, K.C.; Finckh, M.R.; Morris, J.G. Environmental and Health Effects of the Herbicide Glyphosate. Sci. Total Environ. 2018, 616-617, 255-268. [CrossRef] [PubMed]

7. Ohtonen, R.; Munson, A.; Brand, D. Soil Microbial Community Response to Silvicultural Intervention in Coniferous Plantation Ecosystems. Ecol. Appl. 1992, 2, 363-375. [CrossRef]

8. IARC Monograph on Glyphosate. Available online: Https://Www.Iarc.Fr/En/Media-Center/Iarcnews/2016/Glyphosate_ IARC2016.Ph (accessed on 9 December 2021).

9. Xu, J.; Smith, S.; Smith, G.; Wang, W.; Li, Y. Glyphosate Contamination in Grains and Foods: An Overview. Food Control 2019, 106, 106710. [CrossRef]

10. Cahuantzi-Muñoz, S.L.; González-Fuentes, M.A.; Ortiz-Frade, L.A.; Torres, E.; Ţălu, Ş.; Trejo, G.; Méndez-Albores, A. Electrochemical Biosensor for Sensitive Quantification of Glyphosate in Maize Kernels. Electroanalysis 2019, 31, 927-935. [CrossRef]

11. Yáñez-Sedeño, P.; Campuzano, S.; Pingarrón, J.M. Electrochemical Sensors Based on Magnetic Molecularly Imprinted Polymers: A Review. Anal. Chim. Acta 2017, 960, 1-17. [CrossRef]

12. Scheller, F.W.; Zhang, X.; Yarman, A.; Wollenberger, U.; Gyurcsányi, R.E. Molecularly Imprinted Polymer-Based Electrochemical Sensors for Biopolymers. Curr. Opin. Electrochem. 2019, 14, 53-59. [CrossRef]

13. BelBruno, J.J. Molecularly Imprinted Polymers. Chem. Rev. 2018, 119, 94-119. [CrossRef]

14. Janczura, M.; Luliński, P.; Sobiech, M. Imprinting Technology for Effective Sorbent Fabrication: Current State-of-Art and Future Prospects. Materials 2021, 14, 1850. [CrossRef]

15. Leibl, N.; Haupt, K.; Gonzato, C.; Duma, L. Molecularly Imprinted Polymers for Chemical Sensing: A Tutorial Review. Chemosensors 2021, 9, 123. [CrossRef]

16. Spychalska, K.; Zając, D.; Baluta, S.; Halicka, K.; Cabaj, J. Functional Polymers Structures for (Bio) Sensing Application-A Review. Polymers 2020, 12, 1154. [CrossRef]

17. Saylan, Y.; Akgönüllü, S.; Yavuz, H.; Ünal, S.; Denizli, A. Molecularly Imprinted Polymer Based Sensors for Medical Applications. Sensors 2019, 19, 1279. [CrossRef] [PubMed]

18. Prasad, B.B.; Jauhari, D.; Tiwari, M.P. Doubly Imprinted Polymer Nanofilm-Modified Electrochemical Sensor for Ultra-Trace Simultaneous Analysis of Glyphosate and Glufosinate. Biosens. Bioelectron. 2014, 59, 81-88. [CrossRef] [PubMed]

19. Mazouz, Z.; Rahali, S.; Fourati, N.; Zerrouki, C.; Aloui, N.; Seydou, M.; Yaakoubi, N.; Chehimi, M.; Othmane, A.; Kalfat, R. Highly Selective Polypyrrole MIP-Based Gravimetric and Electrochemical Sensors for Picomolar Detection of Glyphosate. Sensors 2017, 17, 2586. [CrossRef] [PubMed]

20. Xu, J.; Zhang, Y.; Wu, K.; Zhang, L.; Ge, S.; Yu, J. A Molecularly Imprinted Polypyrrole for Ultrasensitive Voltammetric Determination of Glyphosate. Microchim. Acta 2017, 184, 1959-1967. [CrossRef]

21. Han, X.-J.; Ji, X.-F.; Zhang, Q.; Sun, J.-W.; Sun, P.-X.; Pan, W.-J.; Wang, J.; Yang, C. Giant “Molecular Capacitor" Arrays-Portable Sensors to Determine Ionizable Compounds. J. Electroanal. Chem. 2020, 865, 114108. [CrossRef]

22. Turiel, E.; Martín-Esteban, A. Molecularly Imprinted Polymers for Sample Preparation: A Review. Anal. Chim. Acta 2010, 668, 87-99. [CrossRef]

23. Dutta, P.K.; Dutta, J.; Tripathi, V. Chitin and Chitosan: Chemistry, Properties and Applications. J. Sci. Ind. Res. 2004, 63, $20-31$.

24. Wang, Y.; Wang, E.; Wu, Z.; Li, H.; Zhu, Z.; Zhu, X.; Dong, Y. Synthesis of Chitosan Molecularly Imprinted Polymers for Solid-Phase Extraction of Methandrostenolone. Carbohydr. Polym. 2014, 101, 517-523. [CrossRef] [PubMed]

25. Wang, X.; Wu, M.; Tang, W.; Zhu, Y.; Wang, L.; Wang, Q.; He, P.; Fang, Y. Simultaneous Electrochemical Determination of Ascorbic Acid, Dopamine and Uric Acid Using a Palladium Nanoparticle/Graphene/Chitosan Modified Electrode. J. Electroanal. Chem. 2013, 695, 10-16. [CrossRef]

26. Zouaoui, F.; Bourouina-Bacha, S.; Bourouina, M.; Abroa-Nemeir, I.; Ben Halima, H.; Gallardo-Gonzalez, J.; El Alami El Hassani, N.; Alcacer, A.; Bausells, J.; Jaffrezic-Renault, N.; et al. Electrochemical Impedance Spectroscopy Determination of Glyphosate Using a Molecularly Imprinted Chitosan. Sens. Actuators B Chem. 2020, 309, 127753. [CrossRef]

27. Zouaoui, F.; Bourouina-Bacha, S.; Bourouina, M.; Alcacer, A.; Bausells, J.; Jaffrezic-Renault, N.; Zine, N.; Errachid, A. Experimental Study and Mathematical Modeling of a Glyphosate Impedimetric Microsensor Based on Molecularly Imprinted Chitosan Film. Chemosensors 2020, 8, 104. [CrossRef] 
28. Zouaoui, F.; Bourouina-Bacha, S.; Bourouina, M.; Jaffrezic-Renault, N.; Zine, N.; Errachid, A. Electrochemical Sensors Based on Molecularly Imprinted Chitosan: A Review. TrAC Trends Anal. Chem. 2020, 130, 115982. [CrossRef]

29. Zouaoui, F.; Bourouina-Bacha, S.; Bourouina, M.; Alcacer, A.; Bausells, J.; Jaffrezic-Renault, N.; Zine, N.; Errachid, A. Electrochemical Impedance Spectroscopy Microsensor Based on Molecularly Imprinted Chitosan Film Grafted on a 4-Aminophenylacetic Acid (CMA) Modified Gold Electrode, for the Sensitive Detection of Glyphosate. Front. Chem. 2021, 9, 621057. [CrossRef] [PubMed]

30. Lefrou, C.; Fabry, P.; Poignet, J.-C. Électrochimie: Concepts Fondamentaux Illustrés, Nouvelle Edition; Collection Grenoble Sciences; EDP Sciences: Les Ulis, France, 2013.

31. Miomandre, F.; Sadki, S.; Audebert, P.; Méallet-Renault, R.; Amatore, C. Électrochimie: Des Concepts Aux Applications, 4th ed.; Sciences sup. Chimie; Dunod: Paris, France, 2019.

32. Sakar, H.; Celik, I.; Balcik Canbolat, C.; Keskinler, B.; Karagunduz, A. Electro-Sorption of Ammonium by a Modified Membrane Capacitive Deionization Unit. Sep. Sci. Technol. 2017, 52, 2591-2599. [CrossRef]

33. Jaffrezic-Renault, N.; Dzyadevych, S.V. Conductometric Microbiosensors for Environmental Monitoring. Sensors 2008, 8, 25692588. [CrossRef]

34. Moreno, T.V.; Malacarne, L.C.; Baesso, M.L.; Qu, W.; Dy, E.; Xie, Z.; Fahlman, J.; Shen, J.; Astrath, N.G. Potentiometric Sensors with Chalcogenide Glasses as Sensitive Membranes: A Short Review. J. Non-Cryst. Solids 2018, 495, 8-18. [CrossRef]

35. Kanyong, P.; Krampa, F.D.; Aniweh, Y.; Awandare, G.A. Enzyme-Based Amperometric Galactose Biosensors: A Review. Microchim. Acta 2017, 184, 3663-3671. [CrossRef]

36. Farghaly, O.A.; Hameed, R.A.; Abu-Nawwas, A.-A.H. Analytical Application Using Modern Electrochemical Techniques. Int. J. Electrochem. Sci. 2014, 9, 3287-3318.

37. Park, S.-M.; Yoo, J.-S. Peer Reviewed: Electrochemical Impedance Spectroscopy for Better Electrochemical Measurements. Anal. Chem. 2003, 75, 455A-461A. [CrossRef] [PubMed]

38. Sacco, A. Electrochemical Impedance Spectroscopy: Fundamentals and Application in Dye-Sensitized Solar Cells. Renew. Sustain. Energy Rev. 2017, 79, 814-829. [CrossRef]

39. Gao, M.; Hazelbaker, M.S.; Kong, R.; Orazem, M.E. Mathematical Model for the Electrochemical Impedance Response of a Continuous Glucose Monitor. Electrochim. Acta 2018, 275, 119-132. [CrossRef]

40. Tkach, V.; de Oliveira, S.C.; de Oliveira, S.C.; Neves, V.S.; Ojani, R.; Yagodynets, P.I. The Electrochemical Oxidation of Procarbazine on Cobalt (III) Oxyhydroxide and Its Mathematical Evaluation. Anal. Bioanal. Electrochem 2016, 8, 432.

41. Los, P.; Laviron, E. The Ac Faradaic Impedance of a Redox System with Langmuirian Adsorption of the Reactants. J. Electroanal Chem. 1997, 432, 85-99. [CrossRef]

42. Lee, M.; Zine, N.; Baraket, A.; Zabala, M.; Campabadal, F.; Caruso, R.; Trivella, M.G.; Jaffrezic-Renault, N.; Errachid, A. A Novel Biosensor Based on Hafnium Oxide: Application for Early Stage Detection of Human Interleukin-10. Sens. Actuators B Chem. 2012, 175, 201-207. [CrossRef]

43. Sapountzi, E. Développement de Nouveaux Supports Basés Sur Des Nanofibres de Matériaux Hybrides Électrofilées Pour Le Développement de Biocapteurs Électrochimiques; HAL Publisher: Lyon, France, 2015.

44. Brug, G.; Van Den Eeden, A.; Sluyters-Rehbach, M.; Sluyters, J. The Analysis of Electrode Impedances Complicated by the Presence of a Constant Phase Element. J. Electroanal. Chem. 1984, 176, 275-295. [CrossRef]

45. Huang, J.; Li, Z.; Liaw, B.Y.; Zhang, J. Graphical Analysis of Electrochemical Impedance Spectroscopy Data in Bode and Nyquist Representations. J. Power Sources 2016, 309, 82-98. [CrossRef]

46. Stoynov, Z.; Vladikova, D. Differential Impedance Analysis; Marin Drinov Academic Publishing House: Sofia, Bulgaria, 2005.

47. Zoltowski, P. On the Electrical Capacitance of Interfaces Exhibiting Constant Phase Element Behaviour. J. Electroanal. Chem. 1998, 443, 149-154. [CrossRef]

48. Jorcin, J.-B. Spectroscopie d'impédance Electrochimique Locale: Caracterisation de La Delamination Des Peintures et de La Corrosion Des Alliages Al-Cu. Ph.D. Thesis, University of Toulouse, Toulouse, France, 2007.

49. Hinderliter, B.R.; Croll, S.G.; Tallman, D.E.; Su, Q.; Bierwagen, G.P. Interpretation of EIS Data from Accelerated Exposure of Coated Metals Based on Modeling of Coating Physical Properties. Electrochim. Acta 2006, 51, 4505-4515. [CrossRef]

50. Terbouche, A.; Lameche, S.; Ait-Ramdane-Terbouche, C.; Guerniche, D.; Lerari, D.; Bachari, K.; Hauchard, D. A New Electrochemical Sensor Based on Carbon Paste Electrode/Ru(III) Complex for Determination of Nitrite: Electrochemical Impedance and Cyclic Voltammetry Measurements. Measurement 2016, 92, 524-533. [CrossRef]

51. Tanujit, B.; Asokan, S. Electrochemical Impedance Spectroscopy Study of AgI-Ag2O-MoO3 Glasses: Understanding the Diffusion, Relaxation, Fragility and Power Law Behavior. arXiv 2019, arXiv:1906.07438. [CrossRef]

52. Shrivastava, A.; Gupta, V. Methods for the Determination of Limit of Detection and Limit of Quantitation of the Analytical Methods. Chron. Young Sci. 2011, 2, 21. [CrossRef]

53. Sellergren, B.; Shea, K.J. Influence of Polymer Morphology on the Ability of Imprinted Network Polymers to Resolve Enantiomers. J. Chromatogr. A 1993, 635, 31-49. [CrossRef]

54. Fellner, P.; Matiašovský, K. On the Temperature Dependence of the Double-Layer Capacitance. Electrochim. Acta 1972, 17, $233-236$. [CrossRef]

55. Pangarov, N.; Christova, I.; Atanasov, M.; Kertov, V. Double-Layer Capacitance Measurements by a Pulse Potentiostatic Method Electrochim. Acta 1967, 12, 717-721. [CrossRef]

56. De Levie, R. On Porous Electrodes in Electrolyte Solutions: I. Capacitance Effects. Electrochim. Acta 1963, 8, 751-780. [CrossRef] 